\title{
Prefrontal cortical and nucleus accumbens contributions to discriminative conditioned suppression of reward-seeking
}

\author{
Patrick T. Piantadosi, Dylan C.M. Yeates, and Stan B. Floresco \\ Department of Psychology and Djavad Mowafaghian Centre for Brain Health, University of British Columbia, Vancouver, \\ British Columbia V6T 1Z4, Canada
}

\begin{abstract}
Fear can potently inhibit ongoing behavior, including reward-seeking, yet the neural circuits that underlie such suppression remain to be clarified. Prior studies have demonstrated that distinct subregions of the rodent medial prefrontal cortex (mPFC) differentially affect fear behavior, whereby fear expression is promoted by the more dorsal prelimbic cortex $(\mathrm{PL})$ and inhibited by the more ventral infralimbic cortex (IL). These $\mathrm{mPFC}$ regions project to subregions of the nucleus accumbens, the core (NACC) and shell (NAcS), that differentially contribute to reward-seeking as well as affective processes that may be relevant to fear expression. Here, we investigated how these mPFC and NAc subregions contribute to discriminative fear conditioning, assessed by conditioned suppression of reward-seeking. Bilateral inactivation of the NACS or PL reduced the expression of conditioned suppression to a shock-associated $\mathrm{CS}_{+}$, whereas NAcC inactivation reduced rewardseeking without affecting suppression. IL inactivation caused a general reduction in conditioned suppression following discriminative conditioning, but not when using a single-stimulus design. Pharmacological disconnection of the PL $\rightarrow$ NAcS pathway revealed that this projection mediates conditioned suppression. These data add to a growing literature implicating discrete cortico-striatal pathways in the suppression of reward-seeking in response to aversive stimuli. Dysfunction within related structures may contribute to aberrant patterns of behavior in psychiatric illnesses including substance use disorders.
\end{abstract}

Fear is a powerful emotional response to potential threat that can exert a pervasive influence over ongoing behavior. For example, fear-inducing stimuli are capable suppressing reward-seeking, which, in an ethological setting, allows animals to avoid potential predation during foraging (Estes and Skinner 1941; Kamin et al. 1963; Whishaw and Dringenberg 1991). In humans, the maladaptive expression of such suppression has been suggested to underlie psychiatric disorders characterized by compulsions or impulse control deficits (Jentsch and Taylor 1999; Lubman et al. 2004; Perry and Carroll 2008; Feil et al. 2010; American Psychiatric Association 2013; Everitt 2014; Limpens et al. 2014; Belin-Rauscent et al. 2016; Figee et al. 2016). Individuals with substance use disorder continue to seek addictive substances despite the incursion of adverse consequences that typically induce fear or anxiety in healthy individuals, curtailing such maladaptive behavior. Investigating the neural basis of such fear-induced behavioral suppression may improve our understanding of behavior from both an ethological and a translational perspective.

Projections from the medial prefrontal cortex (mPFC) to the nucleus accumbens (NAc) may be critical to situations where fear and reinforcement-seeking directly conflict. The prelimbic (PL) and infralimbic (IL) cortices of the mPFC are commonly suggested to promote and inhibit fear expression, respectively (Quirk et al. 2000; Vidal-Gonzalez et al. 2006; Sierra-Mercado et al. 2011; Bukalo et al. 2015), but whether this same dichotomy applies to more complex interactions between appetitive and aversive states is less clear (Resstel et al. 2008; Sangha et al. 2014). These prefrontal subregions provide dense innervation of the NAc, suggesting that this pathway may allow cortico-limbic regions to guide action selection via ventral striatal input to motor affector sites (Mogenson

\section{Corresponding author: floresco@psych.ubc.ca}

Article is online at http://www.learnmem.org/cgi/doi/10.1101//m.051912.120. et al. 1980; Berendse et al. 1992; Brog et al. 1993; Wright et al. 1996; Groenewegen et al. 1999; Vertes 2004). Despite the prime anatomical and physiological arrangement of the NAc to the regulation of appetitive and aversive motivational conflict, experimental data are essentially equivocal regarding its involvement in conditioned fear (Riedel et al. 1997; Parkinson et al. 1999; Schwienbacher et al. 2004; McDannald and Galarce 2011; Rodriguez-Romaguera et al. 2012). Some of this ambiguity may relate to a lack of appreciation for the heterogeneous nature of the NAc itself, which is composed of at least two functionally and anatomically distinct subregions, the nucleus accumbens shell (NAcS) and core (NAcC) (Zahm and Brog 1992; Brog et al. 1993; Floresco 2015). Recent descriptions of the dichotomous nature of these accumbens subnuclei suggest that, although both NAcC and NAcS may be critical for approach behavior, the NAcS preferentially contributes to responsesuppression (Ishikawa et al. 2008; Peters et al. 2008; Ambroggi et al. 2011; Floresco 2015; Piantadosi et al. 2017, 2018). However, it is unknown whether the conditioned suppression of rewardseeking is dependent on neural activity within subregions of the $\mathrm{mPFC}$ and the NAc.

Here, we utilized pharmacological inactivations of the NAcC, NAcS, PL, or IL to assess the contribution of these regions to discriminative conditioned suppression of reward-seeking. We hypothesized that inactivation of the NAcS or PL (but not NAcC or IL) prior to the fear expression test would disinhibit reward-seeking during the presentation of an aversive stimulus, consistent with a

(C) 2020 Piantadosi et al. This article is distributed exclusively by Cold Spring Harbor Laboratory Press for the first 12 months after the full-issue publication date (see http://learnmem.cshlp.org/site/misc/terms.xhtml). After 12 months, it is available under a Creative Commons License (AttributionNonCommercial 4.0 International), as described at http://creativecommons. org/licenses/by-nc/4.0/. 
role for these regions in fear-induced suppression. We then conducted a pharmacological disconnection experiment aimed at isolating the $\mathrm{PL} \rightarrow \mathrm{NAcS}$ pathway responsible for the appropriate expression of conditioned suppression.

\section{Results}

\section{NAcS inactivation}

The experimental timeline of these studies is presented in Figure $1 \mathrm{~A}$, and the location of infusion for each region can be found in Figure 1B. Inactivation of NAcS ( $n=13)$ markedly disrupted the expression of discriminative conditioned suppression, as compared to controls $(n=14)$ (Fig. 2A). Analysis of these data produced a significant CS Type $\times$ Treatment interaction $\left(F_{(1,25)}=5.02, P<0.035\right)$ that was driven by less suppression during presentation of the CS+ for animals in the NAcS inactivation group $\left(F_{(1,25)}=4.24, P=\right.$ 0.05). In contrast, lever-pressing during the CS- did not differ across treatments $\left(F_{(1,25)}=0.20, P>0.66\right)$. Inspection of Figure $2 \mathrm{~A}$ (right) would suggest that NAcS inactivation had a greater effect on fear expression more prominently during the latter presentations of the CS+ compared to the first presentation. However, analyses failed to reveal a significant three-way interaction or any other

\section{Discriminative Fear Conditioning}

A Conditioning (1 day)

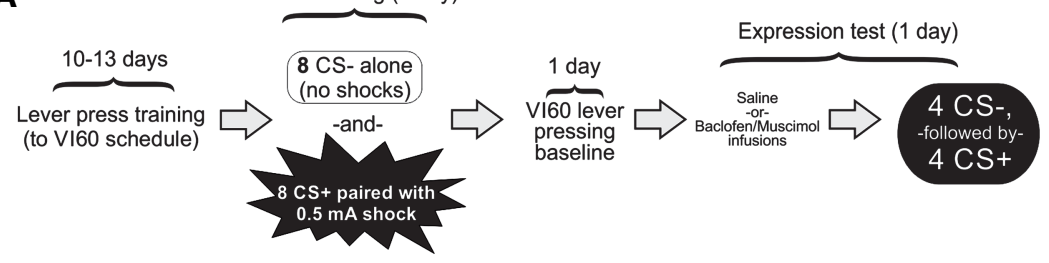

Location of infusions (bilateral inactivations)

B
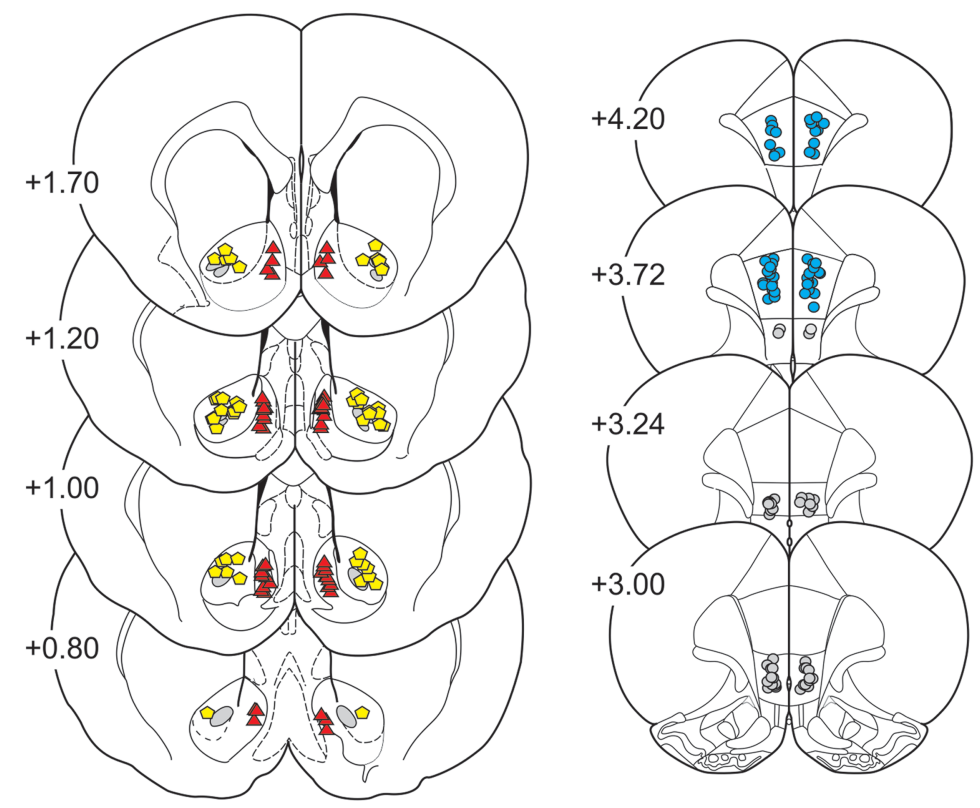

FIGURE 1. Discriminative fear task diagram and histology. $(A)$ Discriminative fear task procedure. (B) Histology figure diagraming location of infusions for animals used in the bilateral inactivation experiment. Red triangles represent NAcS placements, yellow pentagons indicate NAcC placements, blue circles represent PL placements and gray circles represent IL placements. Each dot represents the most ventral extent of the infusion, as observed in Nissl stained sections and the numbers beside each plate represent $\mathrm{mm}$ from bregma. two-way interactions (all $F$-values $<1.3$, all $P$-values $>0.25$ ). NAcS inactivation did not alter the total number of lever-presses made during the session $\left(t_{(25)}=-1.18, P>0.24\right)$, nor the rate of pressing during the initial $5 \mathrm{~min}$ baseline period $\left(t_{(25)}=0.15, P>0.88\right.$; Table 1), indicating that NAcS inactivation did not induce a general disinhibition of reward-seeking. Similarly, there was no change in overall locomotion during the expression test session $\left(t_{(25)}=-1.21\right.$, $P>0.23$; Table 1). Thus, the NAcS was required for responsesuppression during the presentation of an aversive CS+, but not for discriminating between distinct stimuli or general rewardseeking motivation under these conditions.

\section{NAcC inactivation}

In contrast to the impact of NAcS inactivation, inactivation of the adjacent NAcC had no impact on fear expression (Fig. 2B). No main effect of Treatment was observed $\left(F_{(1,19)}=0.05, P>0.84\right)$, indicating that NAcC inactivated rats $(n=9)$ expressed levels of fear comparable to control rats $(n=12)$. Discrimination between the CS- and $\mathrm{CS}+$ was intact, regardless of treatment condition (main effect of CS Type $\left(F_{(1,19)}=102.36, P<0.001\right.$; CS Type $\times$ Treatment interaction $\left.\left(F_{(1,19)}=0.54, P>0.47\right)\right)$. Additionally, there was no significant three-way interaction $\left(F_{(3,57)}=0.80, P>0.50\right)$. However, NAcC inactivation reduced the total number of lever-presses $\left(t_{(19)}=2.23, P<0.04\right)$, and decreased the rate of lever-pressing during the first five min of the session relative to control animals, although this latter effect only approached statistical significance $\left(t_{(19)}=1.74, \quad P>0.09\right.$; Table 1$)$. NAcC inactivation also decreased locomotion $\left(t_{(19)}=2.80, P<0.02\right.$; Table 1$)$. These data suggest that NAcC does not play an integral role in modulating fear responses based on cues predicting safety or an aversive consequence, but does promote behavioral activation, enhancing response vigor during reward-seeking.

\section{PL cortex inactivation}

Like the NAcS, neural activity in the PL cortex was found to be necessary for the appropriate expression of conditioned suppression (Fig. 3A). A significant main effect of Treatment $\left(F_{(1,23)}=13.09\right.$, $P<0.001)$ suggested that $P L$ inactivation $(n=13)$ diminished conditioned suppression, as compared to control animals ( $n=$ $12)$. This was confirmed by a significant CS Type $\times$ Treatment interaction $\left(F_{(1,23)}=\right.$ $11.68, P<0.005)$, with PL inactivation resulting in less fear to the CS+ as compared to control rats $\left(F_{(1,23)}=19.77, P<\right.$ $0.001)$. There was no change in the rate of lever-pressing prior to the first CS presentation $\left(t_{(23)}=0.32, P>0.75\right)$, suggesting that the disinhibition of pressing during the CS+ in PL-inactivated animals was not a result of general behavioral activation (Table 1). Although the total number of lever-presses made during the session was not affected by PL inactivation $\left(t_{(23)}=1.28, P>0.20\right)$, locomotor activity tended to be reduced, although this effect only approached significance $\left(t_{(23)}=-1.76, P>0.09\right.$; Table 1$)$. Thus, PL 
A

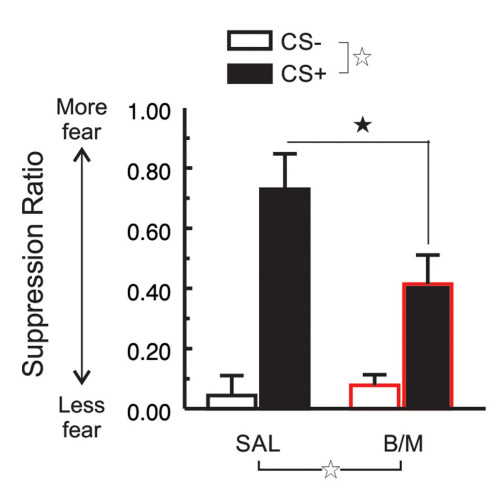

- NAcS Inactivation -

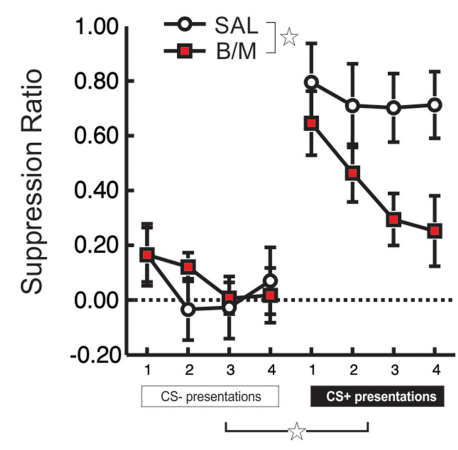

B

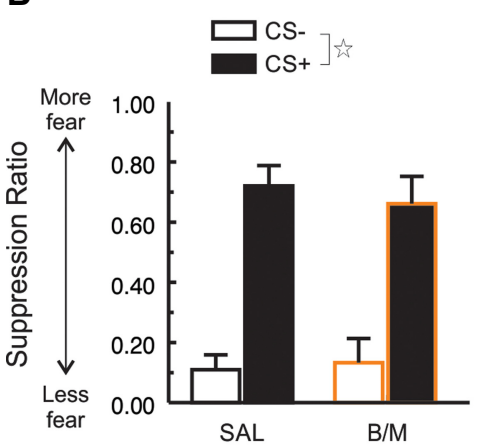

- NAcC Inactivation -

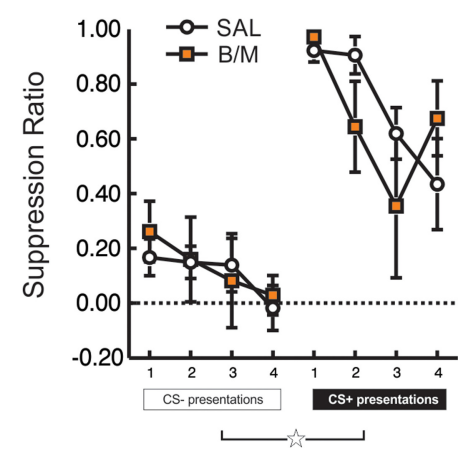

FIGURE 2. NAcS, but not NAcC, mediates the expression of conditioned suppression. (A) NAcS inactivation (B/M) selectively diminished the expression of conditioned suppression toward the CS+, as compared to SAL-infused controls. Mean suppression ratio collapsed across the four of each CS type (left), and displayed for each individual CS (right). (B) Inactivation of the NAcC had no impact on conditioned suppression expression. Mean suppression ratio collapsed across the four of each CS type (left), and displayed for each individual CS (right). Open star represents a main effect of CS Type or Treatment, $P<$ 0.05 . Closed star represents a significant difference between the Treatment conditions on suppression induced by the CS+, $P<0.05$.

activity was necessary for the appropriate expression of fear toward a discriminative $\mathrm{CS}+$, with inactivation markedly reducing the suppression of reward-seeking typically observed during its presentation.

\section{IL cortex inactivation}

Inactivation of IL prior to the expression test session affected conditioned suppression in a manner somewhat distinct from the NAcS or PL (Fig. 3B). A main effect of Treatment was observed $\left(F_{(1,20)}=5.60, P<\right.$ $0.03)$, suggesting that the overall level of suppression during CS presentations was lower in rats receiving IL inactivation ( $n$ $=12)$, as compared to controls $(n=10)$. Unlike inactivation of the more dorsal PL cortex, there was no significant CS Type $\times$ Treatment interaction $\left(F_{(1,20)}=\right.$ $0.16, P>0.69)$. A significant main effect of CS Type $\left(F_{(1,20)}=4.92, P<0.04\right)$ indicated that, despite the lower overall levels of conditioned suppression observed in this experiment, presentation of the CS+ caused more suppression than did presentation of the CS-. As with PL inactivation, there was no significant three-way interaction $\left(F_{(3,60)}=0.95, P>\right.$ 0.42 ). Locomotion was unchanged following IL inactivation $\left(t_{(20)}=0.75, P>\right.$ $0.46)$, as was the rate of lever-pressing during the first $5 \mathrm{~min}$ of the session $\left(t_{(20)}=\right.$ $-0.09, P>0.92)$, and the total number of lever-presses made $\left(t_{(20)}=-0.74, \quad P>\right.$ $0.46)$, suggesting that the impact of IL inactivation on the conditioned suppression of reward-seeking was specific to periods when conditioned stimuli were presented, and not a general effect of behavioral disinhibition (Table 1).

The diminished conditioned suppression following IL manipulation was unexpected, as this region has been implicated more in the extinction of conditioned fear rather than expression (Milad and Quirk 2002; Vidal-Gonzalez et al. 2006; Bukalo et al. 2015). Therefore, we performed an additional experiment to clarify whether the suppression-reducing impact of IL inactivation was specific to discriminative conditioning. When a separate group of rats $(n=8$; location of infusion displayed in Fig. 4A) were subjected to a fear

TABLE 1. Mean $( \pm$ SEM) values for total locomotion, rate of lever-pressing, and total lever-presses during the discriminative fear expression test session

\begin{tabular}{|c|c|c|c|c|c|}
\hline Infusion timeline & Cannula placement & Treatment & $\begin{array}{c}\text { Locomotion } \\
\text { (photobeam breaks) }\end{array}$ & $\begin{array}{l}\text { Lever-press rate } \\
\text { (presses/min) }\end{array}$ & Total lever-presses \\
\hline \multirow{8}{*}{ Bilateral inactivation } & NACS & SAL & $1762( \pm 218)$ & $21.0( \pm 3.6)$ & $760.6( \pm 135.8)$ \\
\hline & & $\mathrm{B} / \mathrm{M}$ & $2285( \pm 388)$ & $20.3( \pm 2.9)$ & $1028.7( \pm 189.2)$ \\
\hline & $\mathrm{NAcC}$ & SAL & $1709( \pm 199)$ & $21.9( \pm 2.9)$ & $751.1( \pm 93.3)$ \\
\hline & & $\mathrm{B} / \mathrm{M}$ & $989( \pm 131)^{*}$ & $15.6( \pm 1.8) \#$ & $483.0( \pm 60.9)^{*}$ \\
\hline & PL & SAL & $1557( \pm 188)$ & $22.2( \pm 3.8)$ & $1003.5( \pm 140.9)$ \\
\hline & & $\mathrm{B} / \mathrm{M}$ & $1176( \pm 115) \#$ & $23.8( \pm 3.0)$ & $1245.9( \pm 126.7)$ \\
\hline & IL & SAL & $1560( \pm 165)$ & $21.5( \pm 2.8)$ & $1029.6( \pm 147.0)$ \\
\hline & & $\mathrm{B} / \mathrm{M}$ & $1365( \pm 195)$ & $21.9( \pm 3.0)$ & $1173.2( \pm 127.9)$ \\
\hline \multirow[t]{2}{*}{ Single-stimulus } & IL & SAL & $2304( \pm 333)$ & $24.4( \pm 5.4)$ & $1450.9( \pm 242.2)$ \\
\hline & & $\mathrm{B} / \mathrm{M}$ & $2412( \pm 518)$ & $25.4( \pm 4.6)$ & $2587.9( \pm 318.2)^{*}$ \\
\hline \multirow[t]{4}{*}{ PL-NACS } & Control & SAL & $1651( \pm 205)$ & $24.3( \pm 3.3)$ & $968.2( \pm 114.7)$ \\
\hline & Contra-Disc & $\mathrm{B} / \mathrm{M}$ & $2155( \pm 272)$ & $23.6( \pm 4.0)$ & $1056.2( \pm 217.1)$ \\
\hline & Ipsi-Disc & $\mathrm{B} / \mathrm{M}$ & $3384( \pm 357)^{\star}$ & $23.5( \pm 3.9)$ & $938.6( \pm 104.1)$ \\
\hline & Unni-Inact & $\mathrm{B} / \mathrm{M}$ & $2455( \pm 371)$ & $19.8( \pm 2.9)$ & $947.5( \pm 144.5)$ \\
\hline
\end{tabular}

* $P<0.05$ versus SAL. \# $P=0.09$. 
A

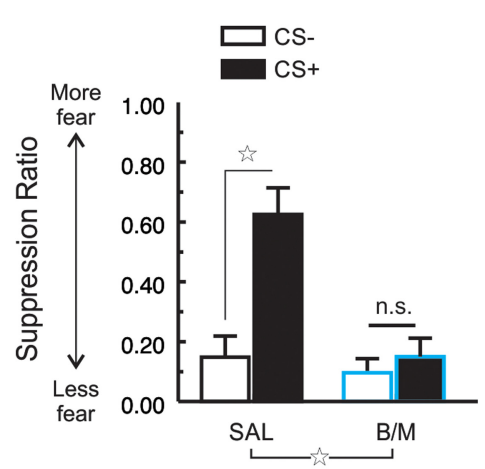

- PL Inactivation -

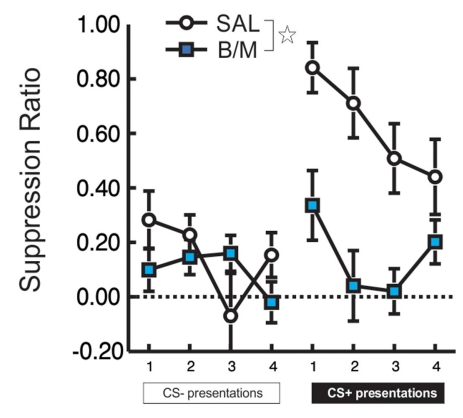

B

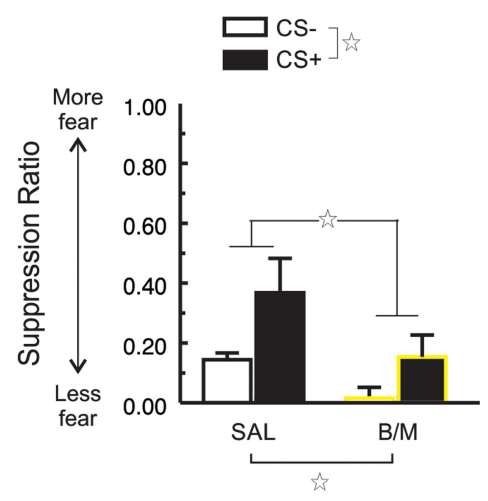

- IL Inactivation -

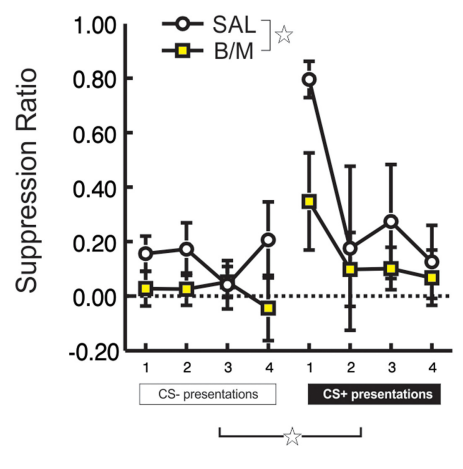

FIGURE 3. Both PL and IL mPFC subregions control the expression of conditioned suppression. $(A) \mathrm{PL}$ cortex was necessary for the appropriate expression of discriminative suppression, as B/M treatment diminished the degree of suppression to the CS+, as compared to SAL treatment. Mean suppression ratio collapsed across the four of each CS type (left), and displayed for each individual CS (right). (B) Inactivation of IL produced a qualitatively similar effect, diminishing overall suppression. Mean suppression ratio collapsed across the four of each CS type (left), and displayed for each individual CS (right). Open star represents a main effect of CS Type or Treatment, $P<0.05$. n.s.: nonsignificant.

conditioning protocol using a single CS, inactivation of the IL did not affect the expression of conditioned suppression compared to control animals ( $n=8$; Fig. $4 \mathrm{~B})$. There was no main effect of Treatment $\left(F_{(1,14)}=1.65, P>0.22\right)$, with both groups extinguishing at a comparable rate as indicated by a significant effect of CS Block $\left(F_{(5,70)}=10.02, P<0.001\right)$, and no significant Treatment $\times$ CS Block interaction $\left(F_{(5,70)}=1.57, P>0.18\right)$. Although the rate of pressing during the first $5 \mathrm{~min}$ of the session was similar across Treatment $\left(t_{(14)}=0.14, P>0.89\right)$, rats receiving IL inactivation made more lever presses throughout the session $\left(t_{(14)}=2.84, P<0.013\right.$; Table 1 ). However, inactivation had no impact on overall locomotor activity $\left(t_{(14)}=0.17, P>0.87 ;\right.$ Table 1$)$. Taken together, these results suggest that neural activity in the IL cortex may play a more selective role in the suppression of reward-seeking in situations requiring the disambiguation of conditioned aversive and neutral stimuli.

\section{PL-NAcS disconnection}

The qualitatively similar effects of PL mPFC and NAcS inactivation on discriminative fear expression led us to probe whether a functional PL $\rightarrow$ NAcS circuit promotes conditioned suppression. Separate groups of animals received contralateral disconnection $(n=9)$, ipsilateral disconnection $(n=9)$, saline $(n=10)$, or unilateral inactivation ( $n=10 ; 5$ PL and 5 NAcS) (Fig. 5A). Disconnection of the PL cortex from the NAcS prior to the expression test dimin- ished conditioned suppression (Fig. 5B; main effect of Treatment $\left(F_{(3,34)}=3.66, P\right.$ $<0.022$, CS Type $\times$ Treatment interaction $\left.\left(F_{(3,34)}=6.46, P<0.001\right)\right)$. There was no three-way interaction $\left(F_{(9,102)}=1.31, P>\right.$ $0.24)$. Follow up simple-main effects analyses on the two-way interaction revealed that this effect was due to a difference between the treatment conditions on $\mathrm{CS}+$ trials $\left(F_{(4,33)}=8.42, P<0.001\right)$, but not CS - trials $\left(F_{(4,33)}=0.66, P>0.58\right)$. Posthoc comparisons with Tukey's test indicated that suppression during the CS+ was similar between saline-treated animals and the unilateral inactivation group $(P>0.80)$. In contrast, the contralateral $(P<0.001)$ and ipsilateral disconnection $(P<0.05)$ groups displayed less conditioned suppression during CS+ presentations compared to controls, although the ipsilateral disconnection and unilateral inactivation groups did not differ $(P>0.15)$. Conversely, contralateral disconnection resulted in significantly less suppression during the CS+ than was observed in rats receiving unilateral inactivation $(P<0.0013)$, suggesting that contralateral disconnections had a greater effect compared to ipsilateral ones. Notably, the impairment in conditioned suppression during the CS+ induced by contralateral $\mathrm{PL} \rightarrow \mathrm{NAcS}$ disconnection appeared to be smaller in magnitude to that induced by bilateral inactivation of the PL (Fig. 2A) This observation was confirmed by a direct, exploratory statistical comparison of the conditioned suppression to the CS+ between the two groups $\left(F_{(1,20)}=17.41, P<0.001\right)$.
A

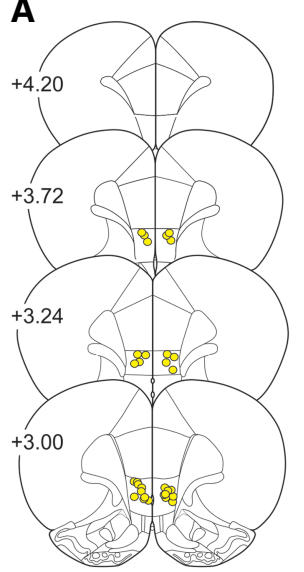

B

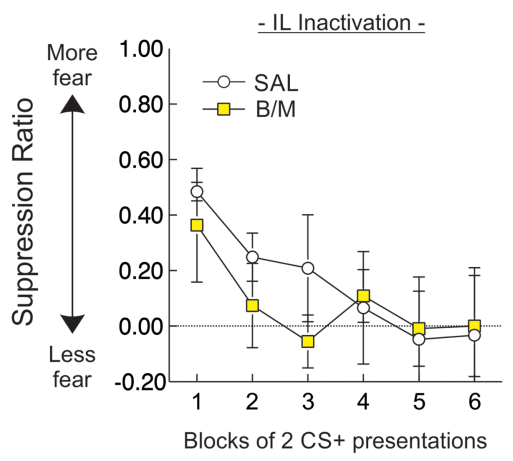

FIGURE 4. IL inactivation has no impact on conditioned suppression expression conducted using a standard, single-stimulus design. $(A)$ Histology schematic for animals in the single-stimulus fear conditioning experiment. Yellow circles represent the ventral extent of infusion into the IL cortex. (B) Infusion of B/M into the IL had no impact on the expression of conditioned suppression when evaluated using a single-stimulus. Suppression data are plotted as blocks of 2 CS+ presentations. 
A

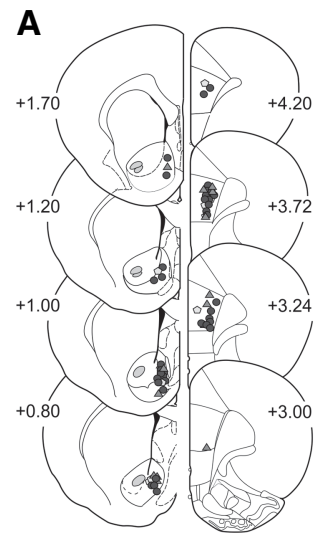

B

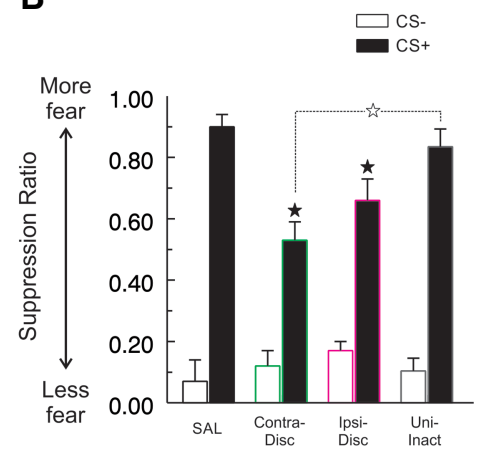

FIGURE 5. A PL-NACS projection contributes to the expression of conditioned suppression. (A) Histology schematic illustrating the ventral extent of each infusion in the NAcS (left) or PL cortex (right). Closed circles represent contralateral infusions (SAL or Contra-Disc), closed triangles represent ipsilateral disconnections (Ipsi-Disc), and gray pentagons represent unilateral inactivation (Uni-Inact). (B) Animals that underwent contralateral disconnection (Contra-Disc) or ipsilateral disconnection (Ipsi-disc) expressed less fear toward the CS+, as compared to control animals (SAL). Conditioned suppression induced by the $\mathrm{CS}+$ in the unilateral inactivation group (Uni-Inact) was significantly higher from contralateral disconnection animals, but did not differ from the Ipsi-Disc or SAL groups. Closed star: comparison of suppression to the CS+, $P<0.05$ between the SAL group and the Contra-Disc or Ipsi-Disc groups, and open star, $P<0.05$ Contra-Disc versus Uni-Inact group.

None of the disconnection treatments affected the total number of lever presses made during the expression test relative to control animals $\left(F_{(3,34)}=0.12, P>0.94\right)$, nor the rate of lever-pressing during the initial portion of the test session $\left(F_{(3,34)}=0.30, P>\right.$ 0.82 ; Table 1). However, locomotor activity did differ as a function of treatment $\left(F_{(3,34)}=7.02, P<0.001\right.$; Table 1$)$, driven by an increase in locomotor activity in the ipsilateral disconnection group, as compared to all other groups (all $P$-values $<0.025$ ). Collectively, these findings confirm that serial communication between the PL and the NAcS aids in suppressing reward-seeking in response to a conditioned aversive CS.

\section{Discussion}

These data demonstrate that separate subregions of the NAc and mPFC uniquely contribute to the expression of discriminative Pavlovian fear, as measured by conditioned suppression. Under control conditions, presentation of an aversive CS+ caused a marked suppression of ongoing reward-seeking, while presentation of a neutral CS- did not alter behavior. Inactivation of either the NAcS or PL diminished the expression of conditioned suppression while having no effect on responding during a neural CS-. Disconnection of these two structures reduced conditioned suppression during the expression test, consistent with the top-down regulation of reward-seeking by this discrete cortico-striatal pathway.

\section{NAc: subregion-specific control of conditioned suppression}

Activity within the NAcS was necessary for the reorganization of behavior during the presentation of an aversive stimulus, but did not affect overall levels of instrumental responding or other measures of activity. These data add to a growing literature implicating the NAcS in the suppression of certain patterns of behavior. For ex- ample, the extinction of reinstated food seeking (Floresco et al. 2008) and the extinction of alcohol or cocaine seeking (Peters et al. 2008; Millan et al. 2010) are dependent upon NAcS integrity. Similarly, refining behavior through the learned cessation of instrumental responding during periods of reward unavailability or nonreinforcement is believed to be mediated by an inhibitory function of the NAcS (Blaiss and Janak 2009; Ambroggi et al. 2011; Ghazizadeh et al. 2012; Floresco et al. 2018). Populations of neurons that encode task-irrelevant stimuli and behaviors during reward-seeking are more numerous in the NAcS, as compared to the NAcC (Ambroggi et al. 2011), which may provide a neuronal mechanism for the NAcS-specific impact on response-inhibition. The ability of the NAcS to suppress inappropriate actions may be mediated in part by projections from dopamine D1-receptor expressing medium spiny neurons to GABAergic neurons in the lateral hypothalamus, as this pathway has recently been shown to regulate the inhibition of alcohol-seeking acquired during extinction (Gibson et al. 2018). Similarly, medial NAcS D1-containing neurons projecting to the medial ventral tegmental area promote behavioral inhibition (Yang et al. 2018). Finally, NAcS activity is critical to withholding actions in the face of potential aversive consequences such as instrumental punishment (Piantadosi et al. 2017; Halladay et al. 2020), predator odor exposure (Blomeley et al. 2017), and inhibitory avoidance (Piantadosi et al. 2018). These previous findings, in addition to the present data support the idea that the NAcS may refine action selection by suppressing inappropriate behaviors, including curtailing reward-seeking in response to potential threats (Floresco 2015).

In contrast, inactivation of the NAcC did not alter conditioned suppression or affect discrimination between the CS+ and CS- under the experimental conditions used here. Although the NAcC has been suggested to control aspects of contextual Pavlovian fear learning (Haralambous and Westbrook, 1999; Wendler et al. 2013), disrupting activity in this subregion does not generally affect the acquisition or expression of fear toward discrete cues (Jongen-Rêlo et al. 2002; Levita et al. 2002; McDannald and Galarce 2011). Given that only cued fear was evaluated in the present experiments, the lack of a NAcC inactivation effect on fear expression is perhaps not surprising. Intriguingly, recent evidence suggests that the NAcC may be recruited to aid in fear expression in situations where cue discrimination (and thus, the appropriate allocation of fear) is made more difficult by the inclusion of an ambiguous CS that is probabilistically associated with foot shock (Ray et al. 2020). When viewed in light of the present data, this suggests that the NAcC may play a more prominent role in discriminative fear expression when threat is probabilistic, but not under more simple conditions when CSs are associated with shock in a deterministic manner.

Notably, manipulation of the NAcC was not without effect, as inactivation decreased both locomotion and reward-seeking (Table 1). Such effects are consistent with previous reports suggesting that this nucleus is involved in reward-related approach and other forms of behavioral activation (Ghods-Sharifi and Floresco 2010; Nicola 2010; Piantadosi et al. 2017, 2018). Indeed, the NAcC is essential for the ability of an appetitive Pavlovian conditioned stimulus to invigorate behavior (Parkinson et al. 2000; Yun et al. 2004; Ambroggi et al. 2011). Intact neural and dopaminergic activity within this nucleus is required for reward-predictive cues to promote efficient instrumental reward-seeking (Nicola 2010; Ambroggi et al. 2011; McGinty et al. 2013). Yet, the present results show that NACC activity is not essential for inhibition of rewardseeking by an aversive Pavlovian conditioned stimulus. Thus, the mechanisms through which the NAcC modulates the impact of Pavlovian cues on behavior appears to be biased toward responsepromotion, rather than response-inhibition. More generally, these findings point to a double dissociation between these two NAc 
subregions in negotiating motivational conflict during rewardseeking under threat, with the NAcS promoting the cessation of ongoing behaviors in response to aversive conditioned stimuli, and the NAcC promoting the vigor of reward-seeking.

\section{Prefrontal contribution to discriminative fear expression}

The finding that PL inactivation disrupted conditioned suppression is in keeping with numerous studies showing that this region of the mPFC is required for the expression of Pavlovian fear (Vidal-Gonzalez et al. 2006; Corcoran and Quirk 2007; Sierra-Mercado et al. 2011; Piantadosi and Floresco 2014; Sangha et al. 2014; Limpens et al. 2015). Models of PL function during the early stages of fear expression and extinction posit that activity within this subregion promotes defensive reactions such as freezing and conditioned suppression in part via interactions with the amygdala (Sierra-Mercado et al. 2011; Pendyam et al. 2013). In keeping with this, PL cortex has been shown to regulate response-inhibition induced by aversive conditioned stimuli during the seeking of cocaine (Chen et al. 2013; Limpens et al. 2015) or alcohol (Seif et al. 2013). Similarly, PL (and potentially IL) cortex appear to mediate the suppression of cocaine-seeking produced by periods of learned cocaine unavailability (Mihindou et al. 2013; Gutman et al. 2014). The present study supports these findings, demonstrating that the fear promoting aspect of the PL cortex is specific to a CS+ when animals are required to discriminate between aversive and neutral cues.

Our observation that IL cortex inactivation decreased conditioned suppression when animals had to discriminate between aversive and neutral cues is somewhat surprising. Using a singlestimulus conditioning procedure, Sierra-Mercado et al. (2011) reported that inactivation of IL prolongs conditioned freezing, an effect opposite to that of PL cortex inactivation. Conversely, stimulation of this region has been shown to decrease fear, enhancing extinction either within-session or across sessions (Milad et al. 2004; Vidal-Gonzalez et al. 2006; Bukalo et al. 2015). However, limited experimental evidence suggests that the fear-induced suppression of reward-seeking, unlike conditioned freezing, is either decreased (as seen here) or unaffected by IL inactivation (Resstel et al. 2008; Sierra-Mercado et al. 2011; Jean-Richard-Dit-Bressel and McNally 2016). Indeed, when we conducted a single-stimulus fear conditioning paradigm (as is common in the literature), conditioned suppression was intact despite IL inactivation (Fig. $4 \mathrm{~B})$. These data suggest that the comparable function of PL and IL observed here may relate to the discriminative nature of our task. In support of this, Sangha et al. (2014) have shown that these prefrontal subregions are not functionally dissociable during performance of a similar Pavlovian discrimination task. Inactivation of either prefrontal subregion altered discriminative fear expression in the same manner, decreasing conditioned freezing during an expression test session, while leaving intact the ability of a neutral, safe cue to ameliorate fear (Sangha et al. 2014). Thus, IL cortex may promote fear during situations that produce conflict between representations evoked by stimuli associated with safety versus fear.

\section{A PL $\rightarrow$ NAcS pathway contributes to conditioned suppression}

Given that the PL cortex projects to the NAcS (Sesack et al. 1989; Brog et al. 1993; Vertes 2004), and that bilateral inactivation of either region induced a qualitatively similar effect on discriminative conditioned suppression, we evaluated whether these regions form a functional circuit that promotes conditioned suppression. We observed that contralateral or ipsilateral disconnection of $\mathrm{PL} \rightarrow$ NAcS circuitry disinhibited reward-seeking in the presence of an aversive $\mathrm{CS}+$, although contralateral disconnection appeared to induce a greater effect. Notably, unilateral inactivation of either region by itself did not significantly disrupt fear expression, indicating that the effects of the disconnection treatment were not attributable to suppression of activity in either the NAcS or PL cortex alone. This combination indicates that both ipsilateral and contralateral communication within this cortico-striatal circuit promotes conditioned suppression of reward-seeking. Previous studies have also reported that ipsilateral disconnection of the NAc from its inputs can alter behavior. For example, ipsilateral manipulation of prefrontal or amygdalar projections to the NAc alters risk/reward decision making, while similar ipsilateral manipulation of prefrontal or ventral subicular projections to the NAc affects the reinstatement of drug-seeking behavior (Bossert et al. 2012, 2016; Jenni et al. 2017; St Onge et al. 2012; van Holstein et al. 2020). One explanation for the similarity between our ipsilateral and contralateral disconnection effects is that a proportion of PFC neurons project to the contralateral hemisphere, meaning that exclusively ipsilateral manipulations will affect some contralaterally projecting neurons. These contralateral and ipsilateral projections may contribute similarly to behavior, as was demonstrated for a ventral PFC-NAcS projection during the context-induced reinstatement of heroin-seeking (Bossert et al. 2012). Notably, in the present study, the magnitude of the $\mathrm{PL} \rightarrow$ NAcS disconnection effect on conditioned suppression (Fig. 5B) appeared to be smaller than that induced by bilateral PL inactivation (Fig. 2A). This suggests that prefrontal control of conditioned fear expression may manifest through multiple output pathways that include the NAcS, as well as the amygdala (Likhtik et al. 2005; Sotres-Bayon and Quirk 2010; Knapska et al. 2012) and periaqueductal gray (Rozeske et al. 2018).

The finding that a PL $\rightarrow$ NAc pathway regulates discriminative conditioned suppression adds a functional correlate to previous work demonstrating that some NAc-projecting mPFC neurons encode the behavioral relevance of an aversive CS+ and a neutral CS(McGinty and Grace 2008). A similar microcircuit between the mPFC and lateral NAcS promotes the suppression of rewardseeking following instrumental punishment (Kim et al. 2017). In that study, a subset of mPFC neurons projecting to the lateral NAcS decreased their activity immediately prior to presses on a punished lever, suggesting that activity within this pathway promotes inhibitory control. Other excitatory inputs to the NAcS, including the amygdala, ventral hippocampus, and paraventricular thalamus have been shown to regulate behavioral inhibition in a variety of settings (Bagot et al. 2015; Millan et al. 2015, 2017; Schumacher et al. 2016, 2018; Yeates et al. 2019; Capuzzo and Floresco 2020; Lafferty et al. 2020), indicating that NAcS may be a hub controlling behavioral output in the face of conflicting motivations. Yet, how glutamatergic projections to the NAcS accomplish such regulation remains unclear. It is possible that PL input differentially affects distinct neuronal subpopulations within the NAcS that may be responsible for action promotion or inhibition, such as medium spiny neurons that express either dopamine D1 or D2 receptor subtypes, as has been shown in the NAc and other striatal regions (Ferguson et al. 2011; Lobo et al. 2011; Kravitz et al. 2012). For example, a projection from ventromedial PFC to the medial NAcS inhibits alcohol-seeking following instrumental punishment experience, potentially by affecting plasticity at D1-receptor expressing medium spiny neurons (Halladay et al. 2020). However, recent work has highlighted that unproductive behaviors governed by the NAcS are not distinctly regulated by particular medium spiny neuron subtypes (Lafferty et al. 2020). Clearly, further study is necessary to identify the circuit mechanisms by which excitatory afferents to the NAcS affect behavior, including the conditioned suppression of reward-seeking. 


\section{Relevance to fear circuitry and psychiatric illness}

The studies reported here utilized a discriminative fear conditioning procedure that is similar to those used in translational settings, where CS- presentations serve as a baseline index of fear, and CS+ presentations induce fear. Using such designs, a relatively conserved fear circuit encompassing the amygdala, prefrontal cortex, and ventral striatum has been identified in the human brain (for reviews, see Delgado et al. 2008b; Peters et al. 2009; Milad and Quirk 2012; Adolphs 2013). Within the PFC, the dorsal anterior cingulate cortex (dACC, Brodmann's area 32) and ventromedial PFC (vmPFC; Brodmann's area 25) have been suggested to be functionally and anatomically homologous to the rodent PL and IL cortex, respectively (Milad and Quirk 2012; Heilbronner et al. 2016). Activity in the dACC occurs in response to CS+ presentations, and this activity (as well as the overall thickness of the region) correlates positively with physiological measures of fear in humans (Milad et al. 2007a). On the other hand, vmPFC activity appears to track extinction learning in humans, as this region displays patterns of activity consistent with deactivation during conditioning, but activation during extinction (Phelps et al. 2004; Milad et al. 2007b). Here, we provide tentative support for the dACC-PL homology suggested by these previous studies, as they apply to the expression of conditioned fear. However, our results seem to suggest that IL cortex performs a similar function, promoting conditioned suppression, in a manner inconsistent with human vmPFC activity. This may again stem from the nature of the defensive reaction measured, as freezing (in rats) and skin conductance or verbal scoring (in humans) do not produce a state of motivational conflict similar to that induced by the conditioned suppression of rewardseeking. Although conditioned suppression paradigms exist in humans (Greville et al. 2013; Allcoat et al. 2015), to date, the relevant functional imaging studies have not been performed to evaluate this hypothesis.

In addition to prefrontal homology, discriminative aversive conditioning produces activity in the human ventral striatum (Jensen et al. 2003; Delgado et al. 2008a,b, 2009; Klucken et al. 2009; Pohlack et al. 2012). This activity is generally differential, with activity increasing in response to a CS+ to a greater degree than a CS-, a pattern which develops over the course of the conditioning session (Klucken et al. 2009). Activity within this nucleus has been shown to translate fear into motivated action, as learning to avoid an aversive CS+ also recruits the NAc (Delgado et al. 2009). In the present study, NAcS activity was necessary for the appropriate expression of discriminative conditioned suppression. Thus, it is possible that the NAc activity observed in human imaging studies of fear learning may reflect preferential activation of the NAcS. Interestingly, diffusion tractography was used to differentiate the NAcS and NAcC in the human brain, with results indicating that the putative NAcS responds in anticipation of thermal pain, while NAcC responds particularly to the offset of a painful stimulus (Baliki et al. 2013). Whether this anticipatory activity relates to behavior is currently unknown, but may partially explain the anticipatory activity observed in NAc prior to presentation of a conditioned aversive stimulus (Jensen et al. 2003).

A number of neuropsychiatric disorders are characterized by dysfunction within cortical and striatal nodes that contribute to abnormal decision-making processes. For example, prefrontal hypofunction appears to be related to inhibitory control deficits in substance abuse (for review, see Goldstein and Volkow 2011). In cocaine users, deficits in inhibitory control are known to correlate with reduced dACC activity, the same region suggested to promote fear expression previously (Kaufman et al. 2003; Hester and Garavan 2004; Li et al. 2008; Goldstein et al. 2009). In rats, hypofunction of the functionally homologous PL cortex recapitulates key aspects of addictive behavior, including drugseeking under threat of punishment (Chen et al. 2013; Limpens et al. 2015). Such a deficit may be related to the loss of a response-inhibitory function within the PL or dACC, as a function of addiction progression. Additionally, meta-analytic studies have consistently shown that patients with anxiety disorders express more fear to a CS- than do control individuals (Lissek et al. 2005; Duits et al. 2015). This deficit may be related to aberrant function of prefrontal circuitry, as trait anxiety is associated with diminished coupling between the amygdala and the vmPFC and a heightened coupling between the amygdala and the dorsomedial PFC, patterns that were opposite that observed in healthy comparison subjects (Kim et al. 2011). Specifically, vmPFC activity is negatively modulated by similarity to a CS+, while dorsomedial PFC activity is positively modulated by the CS+ similarity. This effect has recently been reported to be disturbed in individuals with PTSD, suggesting that imbalanced prefrontal discrimination mechanisms may contribute to anxiety (Kaczkurkin et al. 2017). In the present study, the fear expressed toward a CS- was normal regardless of treatment. Thus, other regions, such as the BLA, which has been shown to encode the valence of discriminative stimuli in rats, nonhuman primates, and humans (Schiller et al. 2008; Genud-Gabai et al. 2013; McHugh et al. 2013; Sangha et al. 2013), may be causally related to fear generalization.

\section{Experimental limitations}

The experiments described here are subject to several important limitations. First, only male rats were tested. Many fear and anxiety-related disorders disproportionately affect women (Kessler et al. 1994, 1995; Breslau et al. 1999; McLean et al. 2011), and rodent studies have demonstrated sex differences in fear expression and its underlying neural circuitry (Rey et al. 2014; Gruene et al. 2015a,b; Fenton et al. 2016). Given that female rats (as compared to males) display distinct active and passive defensive reactions (Gruene et al. 2015a), future studies should compare the relevance of these defensive reactions to situations where reward-seeking and fear overlap, as in conditioned suppression paradigms.

Second, there was a degree of drift in conditioned fear expression across experimental cohorts that complicates direct cross-region comparisons. This was particularly notable in the IL control groups (Figs. 3B, 4B), where conditioned suppression was lower than other SAL control groups. This difference may relate to the damage caused to somewhat distinct regions by cannula implantation, based on the differences in stereotaxic coordinates required to target individual regions. For example, IL implants were conducted without an angle, which likely resulted in damage to the overlying PL cortex. As shown here and elsewhere, PL cortex is necessary for appropriate fear expression, and thus animals with cannula implanted into the IL may display submaximal fear as a result. A similar rationale may explain the differences in fear expressed by control rats in the NAcS (medial cannula placement) versus NAcC (more lateral cannula placement) experiments. Conditioned suppression was somewhat higher in the NAcS SAL group (Fig. 2A, open circles), as compared to the NAcC SAL (Fig. 2B, open circles), or PL SAL (Fig. 3A, open circles) conditions. However, it is less clear how the damage induced by medial NAc cannula placement (mostly affecting posterior PFC and lateral septum) may predispose rats to be more fearful. Critically, our statistical analyses focused primarily on single brain regions, to ensure that differences in fear were assessed in relation to control groups that had comparable cannulation damage (that is, comparing Treatment within IL, rather than across brain regions). 


\section{Conclusion}

Here we demonstrate that distinct subnuclei of the rat NAc and mPFC contribute to aspects of reward-seeking and its conditioned suppression. Both the NAcS and PL were required for the appropriate expression of conditioned suppression, while NAcC activity enhanced response vigor during reward-seeking. IL activity tended to bias rats away from reward-seeking during threat in a manner that was specific to contexts requiring cue discrimination. Finally, we show that a circuit between the PL and NAcS is necessary to instantiate the appropriate inhibition of reward-seeking during aversive stimulus presentations. These findings extend our knowledge of cortico-striatal circuits mediating flexible reward-seeking, identifying prefrontal input to the medial NAc as a critical component of such a network.

\section{Materials and Methods}

\section{Animals}

All procedures were approved by the Animal Care Committee at the University of British Columbia, in accordance with the Canadian Council on Animal Care guidelines. Separate groups of male Long Evans rats (Charles River) arrived weighing 250-300 g. Rats were initially housed in groups (4-5 rats/cage) with ad libitum access to food and water. After 5-10 d of colony acclimatization, rats were stereotaxically implanted with stainless-steel guide cannula, as described below. Upon recovery, rats were singly housed and food-restricted to $\sim 90 \%$ of their free-feeding weight. Rats were allowed to gain weight following this initial period of restriction, such that they were maintained on a delayed growth curve.

\section{Apparatus}

Behavior was assessed using eight standard Med Associates operant chambers, enclosed in sound attenuating chambers $(30.5 \times 24 \times 21$ $\mathrm{cm}$; Med Associates), as previously described (Piantadosi et al. 2017). Each chamber was capable of delivering sucrose reinforcement (45 mg pellet; BioServ), and contained a house light and two $100 \mathrm{~mA}$ cue lights. An auditory speaker allowed for the delivery of discriminative auditory stimuli via a programmable generator (ANL-926, Med Associates). Locomotor activity was measured by four infrared photobeams located just above the grid floor, which was wired to a shock source and solid-state grid scrambler for foot shock delivery.

\section{Stereotaxic surgery and disconnection rationale}

Due to changes in institutional policies regarding anesthesia, rats were anesthetized either with a combination of ketamine/xylazine $(100 / 10 \mathrm{mg} / \mathrm{mL}$ at $100 / 10 \mathrm{mg} / \mathrm{kg}$, i.p.) or a half dose of ketamine/ xylazine (same $\mathrm{mg} / \mathrm{mL}$, i.p) followed by maintenance using Isoflurane anesthetic (2\%-3\% Isoflurane concentration) throughout surgery.

For the bilateral inactivation experiments, twenty-three gauge bilateral stainless-steel guide cannula were implanted into the NAcS, NAcC, PL, or IL, according to the following stereotaxic coordinates (in $\mathrm{mm}$ ):

NAcS—from bregma, AP: +1.3 , ML: \pm 1.0 , from dura, DV: -6.3

NAcC-from bregma, AP: $+1.6, \mathrm{ML}: \pm 1.8$, from dura, DV: -6.3

PL-from bregma: AP +3.2; ML: \pm 0.7 ; from dura: DV: -2.8

IL-from bregma: AP: +2.8 ; ML: \pm 0.7 ; from dura: $\mathrm{DV}:-4.1$

Guide cannula were beveled at the tip to minimize damage when implanted, which in turn would be expected to curtail backflow of infusate to more dorsal regions.

A subsequent series of experiments used a pharmacological disconnection approach to probe whether a functional pathway from the PL to the NAcS may control the expression of conditioned suppression. Briefly, this approach entailed perturbing neural activity in one region (for example, the PL) within one hemisphere, which prevents transmission of task-relevant information to another region of interest (for example, the NAcS). This is combined with an inactivation of an efferent target in the contralateral hemisphere (the NAcS). As a result, direct communication between two brain regions within a neural circuit is disrupted in both hemispheres of the brain following a contralateral disconnection. In a separate group, neural activity can be disrupted within each region in the ipsilateral hemisphere (ipsilateral disconnection), leaving an intact circuit in the opposite hemisphere. Finally, unilateral inactivation of each region individually can be performed to assess whether the disconnection effect was due to the partial loss of a functional pathway, or whether the effect is mediated by a single node within this putative circuit.

For the disconnection experiments, single 23 gauge stainless steel guide cannula were implanted aimed at the PL and NAcS in the contralateral or ipsilateral hemispheres, or unilaterally in the PL or NAcS, according to the stereotaxic coordinates listed above. The particular hemisphere selected for each placement was counterbalanced across experimental conditions, such that equivalent numbers of rats received cannula in each combination of hemispheres.

For all surgical procedures, four stainless-steel skull screws were inundated with dental acrylic to secure cannula in place. Stainless-steel obturators flush with the end of the guide cannula were inserted after surgery. Rats were given 5-10 d to recover from surgery before beginning behavioral training.

\section{Lever training}

The day before their initial operant training session, all rats were provided with $\sim 30$ sucrose pellets in their home cage, to reduce neophobia to the reinforcer. Training was conducted at a consistent time each day. Rats were initially trained to press a lever on the left side of the chamber on a fixed ratio 1 (FR1) schedule of reinforcement to a criterion of 40 total presses during the 30 min session (Fig. 1A). After reaching criterion, rats were trained over three consecutive days on increasing variable interval (VI) schedules, whereby reward was provided after approximately 15 (VI15), 30 (VI30), or 60 (VI60) sec of pressing (one session at each schedule, per day). Rats were then trained on the VI60 schedule for 10-13 d, after which rats received a fear conditioning session. A VI60 schedule engenders a high rate of lever-pressing in rats while maintaining a consistent reward rate, allowing for the accurate assessment of conditioned suppression as a proxy for fear (Kamin et al. 1963; McAllister 1997; Quirk et al. 2000; Piantadosi and Floresco 2014). The house light was illuminated during all sessions, including the test of fear expression.

\section{Discriminative fear conditioning}

\section{Conditioning session}

Rats underwent discriminative fear conditioning in an identical fashion as we have reported previously (Piantadosi and Floresco 2014). During this conditioning session, the reward lever was not inserted into the chamber and no food could be obtained. Thus, even though rats were placed in the same individual chambers throughout training, conditioning, and testing, CS-shock pairings likely were perceived to have occurred in a different context compared to the one where they lever pressed for food and would later be tested in for fear expression. This contextual shift is notable, as previous studies examining the effects of PL/IL inactivation on conditioned suppression have allowed animals to lever-press for food during the fear conditioning session, potentially complicating the dissociation between contextual and cued fear as assessed during the test session (Sierra-Mercado et al. 2011).

Rats were given eight presentations each of a $30 \mathrm{sec}$ neutral conditioned stimulus (CS-; $1 \mathrm{kHz}, 80 \mathrm{~dB}$ tone + cue light illumination, no house light) and a $30 \mathrm{sec}$ aversive conditioned stimulus $(\mathrm{CS}+; 9 \mathrm{kHz}, 80 \mathrm{~dB}$ tone + flashing house light coterminating with a $0.5 \mathrm{~mA}$ foot shock delivered over $0.5 \mathrm{sec}$ ), separated by an average 
interstimulus interval of $180 \mathrm{sec}$ (min: $100 \mathrm{sec}$, max: $240 \mathrm{sec}$ ). CS+ and CS- presentations occurred in a pseudorandom sequence over the course of the conditioning session, with the exception that the last two stimulus presentations were always the CS+ paired with shock. During CS presentations, the house light was turned off to maximize the salience of the visual component of each CS. The day after this conditioning session, animals were given a baseline VI60 session (no foot shocks or conditioned stimuli).

\section{Expression test session}

During the fear expression test, a 5 min baseline VI60 period preceded the presentation of four CS- presentations, followed by four presentations of the CS+ (30 sec each, no foot shock; 5 min interstimulus interval). The suppression of lever-pressing during each CS presentation served as an index of fear, as rats suppress seeking behavior in the presence of an aversive CS+ (Kamin et al. 1963; Quirk et al. 2000; Sierra-Mercado et al. 2011; Piantadosi and Floresco 2014). Suppression was calculated using the formula $[(\mathrm{A}-\mathrm{B}) /(\mathrm{A}+\mathrm{B})]$, where $\mathrm{A}$ was the number of lever-presses made in the 30 sec epoch prior to CS presentation, and $B$ was the number of lever-presses made during the $30 \mathrm{sec}$ CS presentation. A value of 1 indicates complete suppression, while values at 0 or below indicate no suppression or facilitation, respectively. Rarely, rats did not press during the pretone and tone period; a suppression value of 1 was applied to all such instances, as has been done previously (Quirk et al. 2000). An a priori inclusion criteria of greater than 200 presses made during the test session was established, as levels of pressing under this threshold can produce unreliable suppression ratios. Across all experimental cohorts, data from $n=3$ rats were eliminated as a result of this criterion.

\section{Single-stimulus fear conditioning: pretest IL inactivation}

We conducted an additional experiment to ascertain whether inactivation of the IL affected the expression of conditioned suppression under conditions where a single shock-associated stimulus was used during conditioning, as opposed to the discriminative nature of the design used in our other experiments. Animals were implanted with cannula into the IL cortex and given an identical lever training protocol as described above. During the conditioning session, animals received eight presentations of a single, $30 \mathrm{sec} C S+$ (identical to the CS+ used in the discriminative proto$\mathrm{col})$, similar to conditioning procedures typically used to study IL function (e.g., Akirav et al. 2006; Sierra-Mercado et al. 2011). Forty-eight hours later, rats were given a test session. Again, this session started with rats lever pressing for food delivered on a VI60 schedule. Five minutes into the session, rats received the first of 12 presentations of the $30 \mathrm{sec}$ CS+ (no foot shock), each separated by a 3 min interstimulus interval.

\section{Microinfusion}

All animals underwent mock infusions 10 min prior to the final VI60 session before discriminative conditioning, as described previously (Piantadosi and Floresco 2014). On the infusion day, stainless-steel injectors extending $0.8 \mathrm{~mm}$ beyond the guide cannula were lowered into the region of interest. For the bilateral inactivation experiments, rats received infusions of $0.9 \%$ saline (SAL; $0.3 \mu \mathrm{L} /$ side), or a solution containing the $\mathrm{GABA}_{\mathrm{B}}$-receptor agonist baclofen and the $\mathrm{GABA}_{\mathrm{A}}$-receptor agonist muscimol (B/M; $75 \mathrm{ng} /$ $\mu \mathrm{L}$ of each drug at a volume of $0.3 \mu \mathrm{L} /$ side). Infusions were conducted over $45 \mathrm{sec}$, with injectors left in place for an additional $60 \mathrm{sec}$ to allow for diffusion. The surgical and microinfusion procedures used here are identical or similar to published reports used to dissociate between these and other closely apposed brain regions on a wide variety of behavioral measures (Floresco et al. 2008, 2018; Stopper and Floresco 2011; Dalton et al. 2014, 2016; Piantadosi et al. 2017, 2018; van Holstein and Floresco 2020). Electrophysiological and immunohistochemical studies estimate the functional spread of GABA agonist-induced neural inactivations to be $\sim 1 \mathrm{~mm}$ (Martin and Ghez 1999; Allen et al. 2008; Hamel et al. 2017). Implantation coordinates in the present study were chosen in part to minimize potential spread into neighboring regions.

For the disconnection experiment, control rats received unilateral infusions of $0.9 \%$ SAL into the PL and contralateral NAcS $(0.3 \mu \mathrm{L} /$ side). Disconnection animals received infusion of $\mathrm{B} / \mathrm{M}$ ( $75 \mathrm{ng} / \mu \mathrm{L}$ of each drug at a volume of $0.3 \mu \mathrm{L} /$ side) into the contralateral PL and NAcS (contralateral disconnection), or ipsilateral PL and NAcS (ipsilateral disconnection). A separate group underwent unilateral inactivations of the PL or NAcS (same infusion parameters). Infusion timing was identical to the procedures described previously.

\section{Histology}

All rats were euthanized with $\mathrm{CO}_{2}$, brains were removed and fixed in a $4 \%$ phosphate buffered formalin solution. Brains were sectioned at $50 \mu \mathrm{m}$, following which tissue was mounted and Nissl stained using Cresyl Violet. Placements were examined under a light microscope.

\section{Data analysis}

For the bilateral inactivation experiments, the suppression ratio during each CS presentation during the expression test was analyzed using between/within-subjects three-way ANOVAs with Treatment group (SAL vs. B/M) as the between-subjects variable, and CS Type (CS+ vs. CS-) and CS Number (1-4) as the withinsubjects variables. Separate ANOVAs were conducted on data from animals infused within each brain region (NAcS, NAcC, PL, and IL). For the single-stimulus IL inactivation experiment, suppression ratios for each of the $12 \mathrm{CS}+$ presentations were calculated and binned into six separate bins of two CS+ presentations. These data were analyzed via a two-way ANOVA, with Treatment group (SAL vs. B/M) as the between-subjects variable, and CS Block (1-6) as the within-subjects variable. Follow-up simple main effects analyses were conducted using one-way ANOVAs or $t$-tests, where appropriate. Locomotion (photobeam breaks/session) during the conditioning session or expression test were analyzed using separate independent samples $t$-tests. The rate of lever-pressing (presses/min) in the first $5 \mathrm{~min}$ of the expression test session and the total number of lever-presses made during the session were analyzed in an identical fashion.

Analysis of the disconnection experiment was identical, with the exception that the between-subjects Treatment factor was made up of four levels: saline, contralateral disconnection, ipsilateral disconnection, unilateral inactivation. There was no significant difference between the mean suppression ratio during the CS - and CS+ for animals in the unilateral PL inactivation group (CS-: $0.07 \pm 0.06$ SEM, CS+: $0.82 \pm 0.10$ SEM) versus the unilateral NAcS inactivation group (CS-: $0.14 \pm 0.06$ SEM, CS+: $0.85 \pm 0.08$ SEM) $\left(F_{(1,8)}=0.39, P>0.55\right)$; therefore these groups were combined into a single unilateral inactivation group for all analyses. All other analyses were conducted as described previously for the bilateral inactivation experiments.

\section{Acknowledgments}

This work was supported by a Discovery Grant (RGPIN2018-04295) from the Natural Sciences and Engineering Research Council of Canada to S.B.F. and a University of British Columbia Doctoral Fellowship to P.T.P. We thank Maric T. Tse, Katie Pezarro, Mathew Wilkins, and Magdalen Schluter for their assistance with behavioral testing.

\section{References}

Adolphs R. 2013. The biology of fear. Curr Biol 23: R79-R93. doi:10.1016/j .cub.2012.11.055

Akirav I, Raizel H, Maroun M. 2006. Enhancement of conditioned fear extinction by infusion of the GABA(A) agonist muscimol into the rat prefrontal cortex and amygdala. Eur J Neurosci 23: 758-764. doi:10 $.1111 / \mathrm{j} .1460-9568.2006 .04603 . \mathrm{x}$ 
Allcoat D, Greville WJ, Newton PM, Dymond S. 2015. Frozen with fear: conditioned suppression in a virtual reality model of human anxiety Behav Process 118: 98-101. doi:10.1016/j.beproc.2015.06.011

Allen TA, Narayanan NS, Kholodar-Smith DB, Zhao Y, Laubach M, Brown TH. 2008. Imaging the spread of reversible brain inactivations using fluorescent muscimol. J Neurosci Methods 171: 30-38. doi:10 .1016/j.jneumeth.2008.01.033

Ambroggi F, Ghazizadeh A, Nicola SM, Fields HL. 2011. Roles of nucleus accumbens core and shell in incentive-cue responding and behavioral inhibition. J Neurosci 31: 6820-6830. doi:10.1523/ JNEUROSCI.6491-10.2011

American Psychiatric Association. 2013. The Diagnostic and Statistical Manual of Mental Disorders: DSM 5. American Psychiatric Press, Washington, D C.

Bagot RC, Parise EM, Peña CJ, Zhang HX, Maze I, Chaudhury D, Persaud B, Cachope R, Bolaños-Guzmán CA, Cheer JF, et al. 2015. Ventral hippocampal afferents to the nucleus accumbens regulate susceptibility to depression. Nat Commun 6: 7062. doi:10.1038/ncomms8062

Baliki MN, Mansour A, Baria AT, Huang L, Berger SE, Fields HL, Apkarian AV. 2013. Parceling human accumbens into putative core and shell dissociates encoding of values for reward and pain. J Neurosci 33: 1638316393. doi:10.1523/JNEUROSCI.1731-13.2013

Belin-Rauscent A, Fouyssac M, Bonci A, Belin D. 2016. How preclinical models evolved to resemble the diagnostic criteria of drug addiction. Biol Psychiatry 79: 39-46. doi:10.1016/j.biopsych.2015.01.004

Berendse HW, Galis-de Graaf Y, Groenewegen HJ. 1992. Topographical organization and relationship with ventral striatal compartments of prefrontal corticostriatal projections in the rat. J Comp Neurol 316: 314-347. doi:10.1002/cne.903160305

Blaiss CA, Janak PH. 2009. The nucleus accumbens core and shell are critical for the expression, but not the consolidation, of Pavlovian conditioned approach. Behav Brain Res 200: 22-32. doi:10.1016/j.bbr.2008.12.024

Blomeley C, Garau C, Burdakov D. 2017. Accumbal D2 cells orchestrate innate risk-avoidance according to orexin signals. Nat Neurosci 21: 29-32. doi:10.1038/s41593-017-0023-y

Bossert JM, Stern AL, Theberge FRM, Marchant NJ, Wang H-L, Morales M, Shaham Y. 2012. Role of projections from ventral medial prefrontal cortex to nucleus accumbens shell in context-induced reinstatement of heroin seeking. J Neurosci 32: 4982-4991. doi:10.1523/JNEUROSCI $.0005-12.2012$

Bossert JM, Adhikary S, St. Laurent R, Marchant NJ, Wang HL, Morales M, Shaham Y. 2016. Role of projections from ventral subiculum to nucleus accumbens shell in context-induced reinstatement of heroin seeking in rats. Psychopharmacology (Berl) 233: 1991-2004. doi:10.1007/ s00213-015-4060-5

Breslau N, Chilcoat HD, Kessler RC, Peterson EL, Lucia VC. 1999. Vulnerability to assaultive violence: further specification of the sex difference in post-traumatic stress disorder. Psychol Med 29: 813-821. doi:10.1017/S0033291799008612

Brog JS, Salyapongse A, Deutch AY, Zahm DS. 1993. The patterns of afferent innervation of the core and shell in the "accumbens" part of the rat ventral striatum: immunohistochemical detection of retrogradely transported fluoro-gold. J Comp Neurol 338: 255-278. doi:10.1002/cne .903380209

Bukalo O, Pinard CR, Silverstein S, Brehm C, Hartley ND, Whittle N, Colacicco G, Busch E, Patel S, Singewald N, et al. 2015. Prefrontal inputs to the amygdala instruct fear extinction memory formation. Sci Adv 1: e1500251. doi:10.1126/sciadv.1500251

Capuzzo G, Floresco SB. 2020. Prelimbic and infralimbic prefrontal regulation of active and inhibitory avoidance and reward-seeking. $J$ Neurosci 40: 4773-4787. doi:10.1523/JNEUROSCI.0414-20.2020

Chen BT, Yau HJ, Hatch C, Kusumoto-Yoshida I, Cho SL, Hopf FW, Bonci A. 2013. Rescuing cocaine-induced prefrontal cortex hypoactivity prevents compulsive cocaine seeking. Nature 496: 359-362. doi:10.1038/ nature12024

Corcoran KA, Quirk GJ. 2007. Activity in prelimbic cortex is necessary for the expression of learned, but not innate, fears. J Neurosci 27: 840-844. doi:10.1523/JNEUROSCI.5327-06.2007

Dalton GL, Phillips AG, Floresco SB. 2014. Preferential involvement by nucleus accumbens shell in mediating probabilistic learning and reversal shifts. J Neurosci 34: 4618-4626. doi:10.1523/JNEUROSCI $.5058-13.2014$

Dalton GL, Wang NY, Phillips AG, Floresco SB. 2016. Multifaceted contributions by different regions of the orbitofrontal and medial prefrontal cortex to probabilistic reversal learning. J Neurosci 36: 19962006. doi:10.1523/JNEUROSCI.3366-15.2016

Delgado MR, Li J, Schiller D, Phelps EA. 2008a. The role of the striatum in aversive learning and aversive prediction errors. Philos Trans $R$ Soc Lond $B$ Biol Sci 363: 3787-3800. doi:10.1098/rstb.2008.0161

Delgado MR, Nearing KI, LeDoux JE, Phelps EA. 2008b. Neural circuitry underlying the regulation of conditioned fear and its relation to extinction. Neuron 59: 829-838. doi:10.1016/j.neuron.2008.06.029
Delgado MR, Jou RL, Ledoux JE, Phelps EA. 2009. Avoiding negative outcomes: tracking the mechanisms of avoidance learning in humans during fear conditioning. Front Behav Neurosci 3: 33. doi:10.3389/neuro 08.033 .2009

Duits P, Cath DC, Lissek S, Hox JJ, Hamm AO, Engelhard IM, van den Hout MA, Baas JMP. 2015. Updated meta-analysis of classical fear conditioning in the anxiety disorders. Depress Anxiety 32: 239-253. doi: $10.1002 /$ da. 22353

Estes WK, Skinner BF. 1941. Some quantitative properties of anxiety. J Exp Psychol 29: 390-400. doi:10.1037/h0062283

Everitt BJ. 2014. Neural and psychological mechanisms underlying compulsive drug seeking habits and drug memories-indications for novel treatments of addiction. Eur J Neurosci 40: 2163-2182. doi:10 $.1111 /$ ejn.12644

Feil J, Sheppard D, Fitzgerald PB, Yücel M, Lubman DI, Bradshaw JL. 2010. Addiction, compulsive drug seeking, and the role of frontostriatal mechanisms in regulating inhibitory control. Neurosci Biobehav Rev 35: 248-275. doi:10.1016/j.neubiorev.2010.03.001

Fenton GE, Halliday DM, Mason R, Bredy TW, Stevenson CW. 2016. Sex differences in learned fear expression and extinction involve altered $\gamma$ oscillations in medial prefrontal cortex. Neurobiol Learn Mem 135: 6672. doi:10.1016/j.nlm.2016.06.019

Ferguson SM, Eskenazi D, Ishikawa M, Wanat MJ, Phillips PEM, Dong Y, Roth BL, Neumaier JF. 2011. Transient neuronal inhibition reveals opposing roles of indirect and direct pathways in sensitization. Nat Neurosci 14: 22-24. doi:10.1038/nn.2703

Figee M, Pattij T, Willuhn I, Luigjes J, van den Brink W, Goudriaan A, Potenza MN, Robbins TW, Denys D. 2016. Compulsivity in obsessive-compulsive disorder and addictions. Eur Neuropsychopharmacol 26: 856-868. doi:10.1016/ j.euroneuro.2015.12.003

Floresco SB. 2015. The nucleus accumbens: an interface between cognition, emotion, and action. Annu Rev Psychol 66: 25-52. doi:10.1146/ annurev-psych-010213-115159

Floresco SB, McLaughlin RJ, Haluk DM. 2008. Opposing roles for the nucleus accumbens core and shell in cue-induced reinstatement of food-seeking behavior. Neuroscience 154: 877-884. doi:10.1016/j .neuroscience.2008.04.004

Floresco SB, Montes DR, Tse MMT, Van Holstein M. 2018. Differential contributions of nucleus accumbens subregions to cue-guided risk/ reward decision making and implementation of conditional rules. $J$ Neurosci 38: 1901-1914. doi:10.1523/JNEUROSCI.3191-17.2018

Genud-Gabai R, Klavir O, Paz R. 2013. Safety signals in the primate amygdala. J Neurosci 33: 17986-17994. doi:10.1523/JNEUROSCI $.1539-13.2013$

Ghazizadeh A, Ambroggi F, Odean N, Fields HL. 2012. Prefrontal cortex mediates extinction of responding by two distinct neural mechanisms in accumbens shell. J Neurosci 32: 726-737. doi:10.1523/JNEUROSCI $.3891-11.2012$

Ghods-Sharifi S, Floresco SB. 2010. Differential effects on effort discounting induced by inactivations of the nucleus accumbens core or shell. Behav Neurosci 124: 179-191. doi:10.1037/a0018932

Gibson GD, Prasad AA, Jean-Richard-dit-Bressel P, Yau JOY, Millan EZ, Liu Y, Campbell EJ, Lim J, Marchant NJ, Power JM, et al. 2018. Distinct accumbens shell output pathways promote versus prevent relapse to alcohol seeking. Neuron 98: 512-520.e6. doi:10.1016/j.neuron.2018 .03 .033

Goldstein RZ, Volkow ND. 2011. Dysfunction of the prefrontal cortex in addiction: neuroimaging findings and clinical implications. Nat Rev Neurosci 12: 652-669. doi:10.1038/nrn3119

Goldstein RZ, Alia-Klein N, Tomasi D, Carrillo JH, Maloney T, Woicik PA, Wang R, Telang F, Volkow ND. 2009. Anterior cingulate cortex hypoactivations to an emotionally salient task in cocaine addiction. Proc Natl Acad Sci 106: 9453-9458. doi:10.1073/pnas.0900491106

Greville WJ, Newton PM, Roche B, Dymond S. 2013. Conditioned suppression in a virtual environment. Comput Hum Behav 29: 552-558. doi:10.1016/j.chb.2012.11.016

Groenewegen HJ, Wright CI, Beijer AVJ, Voorn P. 1999. Convergence and segregation of ventral striatal inputs and outputs. Ann N Y Acad Sci 877: 49-63. doi:10.1111/j.1749-6632.1999.tb09260.x

Gruene TM, Flick K, Stefano A, Shea SD, Shansky RM. 2015a. Sexually divergent expression of active and passive conditioned fear responses in rats. Elife 4: e11352. doi:10.7554/elife.11352

Gruene TM, Roberts E, Thomas V, Ronzio A, Shansky RM. 2015b. Sex-specific neuroanatomical correlates of fear expression in prefrontal-amygdala circuits. Biol Psychiatry 78: 186-193. doi:10.1016/j .biopsych.2014.11.014

Gutman AL, Ewald VA, Cosme CV, Worth WR, Lalumiere RT. 2014. The infralimbic and prelimbic cortices contribute to the inhibitory control of cocaine-seeking behavior during a discriminative stimulus task in rats. Addict Biol 22: 1719-1730. doi:10.1111/adb.12434 
Halladay LR, Kocharian A, Piantadosi PT, Authement ME, Lieberman AG, Spitz NA, Coden K, Glover LR, Costa VD, Holmes A. 2020. Prefrontal regulation of punished ethanol self-administration. Biol Psychiatry 87: 967-978. doi:10.1016/j.biopsych.2019.10.030

Hamel L, Thangarasa T, Samadi O, Ito R. 2017. Caudal nucleus accumbens core is critical in the regulation of cue-elicited approach-avoidance decisions. eNeuro 4: 1-14. doi:10.1523/ENEURO.0330-16.2017

Haralambous T, Westbrook RF. 1999. An infusion of bupivacaine into the nucleus accumbens disrupts the acquisition but not the expression of contextual fear conditioning. Behav Neurosci 113: 925-940. doi:10 $.1037 / 0735-7044.113 .5 .925$

Heilbronner SR, Rodriguez-Romaguera J, Quirk GJ, Groenewegen HJ, Haber SN. 2016. Circuit-based corticostriatal homologies between rat and primate. Biol Psychiatry 80: 509-521. doi:10.1016/j.biopsych .2016 .05 .012

Hester R, Garavan H. 2004. Executive dysfunction in cocaine addiction: evidence for discordant frontal, cingulate, and cerebellar activity. $J$ Neurosci 24: 11017-11022. doi:10.1523/JNEUROSCI.3321-04.2004

Ishikawa A, Ambroggi F, Nicola SM, Fields HL. 2008. Dorsomedial prefrontal cortex contribution to behavioral and nucleus accumbens neuronal responses to incentive cues. J Neurosci 28: 5088-5098. doi:10.1523/ JNEUROSCI.0253-08.2008

Jean-Richard-Dit-Bressel P, McNally GP. 2016. Lateral, not medial, prefrontal cortex contributes to punishment and aversive instrumental learning. Learn Mem 23: 607-617. doi:10.1101/LM.042820.116

Jenni NL, Larkin JD, Floresco SB. 2017. Prefrontal dopamine D1 and D2 receptors regulate dissociable aspects of decision making via distinct ventral striatal and amygdalar circuits. J Neurosci 37: 6200-6213. doi:10 $.1523 /$ JNEUROSCI.0030-17.2017

Jensen J, McIntosh AR, Crawley AP, Mikulis DJ, Remington G, Kapur S. 2003. Direct activation of the ventral striatum in anticipation of aversive stimuli. Neuron 40: 1251-1257. doi:10.1016/S0896-6273(03)00724-4

Jentsch JD, Taylor JR. 1999. Impulsivity resulting from frontostriatal dysfunction in drug abuse: implications for the control of behavior by reward-related stimuli. Psychopharmacology (Berl) 146: 373-390. doi:10 $.1007 /$ PL00005483

Jongen-Rêlo AL, Kaufmann S, Feldon J. 2002. A differential involvement of the shell and core subterritories of the nucleus accumbens of rats in attentional processes. Neuroscience 111: 95-109. doi:10.1016/ S0306-4522(01)00521-8

Kaczkurkin AN, Burton PC, Chazin SM, Manbeck AB, Espensen-sturges T, Cooper SE, Sponheim SR, Lissek S. 2017. Neural substrates of overgeneralized conditioned fear in PTSD. Am J Psychiatry 1742: 125134. doi:10.1176/appi.ajp.2016.15121549

Kamin LJ, Brimer CJ, Black AH. 1963. Conditioned suppression as a monitor of fear of the CS in the course of avoidance training. J Comp Phyisol Psychol 56: 497-501. doi:10.1037/h0047966

Kaufman JN, Ross TJ, Stein EA, Garavan H. 2003. Cingulate hypoactivity in cocaine users during a GO-NOGO task as revealed by event-related functional magnetic resonance imaging. J Neurosci 23: 7839-7843. doi:10.1523/JNEUROSCI.23-21-07839.2003

Kessler RC, McGonagle KA, Zhao S, Nelson CB, Hughes M, Eshleman S, Wittchen HU, Kendler KS. 1994. Lifetime and 12-month prevalence of DSM-III-R psychiatric disorders in the United States: results from the national comorbidity survey. Arch Gen Psychiatry 51: 8-19. doi:10.1001/ archpsyc. 1994.03950010008002

Kessler RC, Sonnega A, Bromet E, Hughes M, Nelson C. 1995. Posttraumatic stress disorder in the national comorbidity survey. Arch Gen Psychiatry 52: 1048-1060. doi:10.1017/СBO9781107415324.004

Kim MJ, Gee DG, Loucks RA, Davis FC, Whalen PJ. 2011. Anxiety dissociates dorsal and ventral medial prefrontal cortex functional connectivity with the amygdala at rest. Cereb Cortex 21: 1667-1673. doi:10.1093/cercor/ bhq237

Kim CK, Ye L, Jennings JH, Pichamoorthy N, Tang DD, Yoo AW, Ramakrishnan C, Deisseroth K. 2017. Molecular and circuit-dynamical identification of top-down neural mechanisms for restraint of reward seeking. Cell 1-15. doi:10.1016/j.cell.2017.07.020

Klucken T, Tabbert K, Schweckendiek J, Merz CJ, Kagerer S, Vaitl D, Stark R. 2009. Contingency learning in human fear conditioning involves the ventral striatum. Hum Brain Mapp 30: 3636-3644. doi:10.1002/hbm .20791

Knapska E, Macias M, Mikosz M, Nowak A, Owczarek D, Wawrzyniak M, Pieprzyk M, Cymerman IA, Werka T, Sheng M, et al. 2012. Functional anatomy of neural circuits regulating fear and extinction. Proc Natl Acad Sci 109: 17093-17098. doi:10.1073/pnas.1202087109

Kravitz AV, Tye LD, Kreitzer AC. 2012. Distinct roles for direct and indirect pathway striatal neurons in reinforcement. Nat Neurosci 15: 816-818. doi: $10.1038 / \mathrm{nn} .3100$

Lafferty CK, Yang AK, Mendoza JA, Britt JP. 2020. Nucleus Accumbens Cell Type- and Input-Specific Suppression of Unproductive Reward Seeking. Cell Rep 30: 3729-3742.e3. doi:10.1016/j.celrep.2020.02.095
Levita L, Dalley JW, Robbins TW. 2002. Disruption of Pavlovian contextual conditioning by excitotoxic lesions of the nucleus accumbens core. Behav Neurosci 116: 539-552. doi:10.1037/0735-7044.116.4.539

Li CS, Huang C, Yan P, Bhagwagar Z, Milivojevic V, Sinha R. 2008. Neural correlates of impulse control during stop signal inhibition in cocaine-dependent men. Neuropsychopharmacology 33: 1798-1806. doi:10.1038/sj.npp. 1301568

Likhtik E, Pelletier JG, Paz R, Paré D. 2005. Prefrontal control of the amygdala. J Neurosci 25: 7429-7437. doi:10.1523/JNEUROSCI $.2314-05.2005$

Limpens JHW, Schut EHS, Voorn P, Vanderschuren LJMJ. 2014. Using conditioned suppression to investigate compulsive drug seeking in rats. Drug Alcohol Depend 142: 314-324. doi:10.1016/j.drugalcdep .2014 .06 .037

Limpens JHW, Damsteegt R, Broekhoven MH, Voorn P, Vanderschuren LJMJ. 2015. Pharmacological inactivation of the prelimbic cortex emulates compulsive reward seeking in rats. Brain Res 1628: $210-218$. doi:10.1016/j.brainres.2014.10.045

Lissek S, Powers AS, McClure EB, Phelps EA, Woldehawariat G, Grillon C, Pine DS. 2005. Classical fear conditioning in the anxiety disorders: a meta-analysis. Behav Res Ther 43: 1391-1424. doi:10.1016/j .brat.2004.10.007

Lobo MK, Iii HEC, Chaudhury D, Friedman AK, Sun H, Damez-werno D, Dietz DM, Zaman S, Koo JW, Kennedy PJ, et al. 2011. Cell type specific loss of BDNF signaling mimics optogenetic control of cocaine reward. Science 330: 385-390. doi:10.1126/science.1188472.Cell

Lubman DI, Yücel M, Pantelis C. 2004. Addiction, a condition of compulsive behaviour? Neuroimaging and neuropsychological evidence of inhibitory dysregulation. Addiction 99: 1491-1502. doi:10.1111/j .1360-0443.2004.00808.x

Martin JH, Ghez C. 1999. Pharmacological inactivation in the analysis of the central control of movement. J Neurosci Methods 86: 145-159. doi:10 $.1016 /$ S0165-0270(98)00163-0

McAllister KH. 1997. A single administration of d-amphetamine prior to stimulus pre-exposure and conditioning attenuates latent inhibition. Psychopharmacology (Berl) 130: 79-84. doi:10.1007/s002130050213

McDannald MA, Galarce EM. 2011. Measuring Pavlovian fear with conditioned freezing and conditioned suppression reveals different roles for the basolateral amygdala. Brain Res 1374: $82-89$. doi:10.1016/j .brainres.2010.12.050

McGinty VB, Grace AA. 2008. Selective activation of medial prefrontal-to-accumbens projection neurons by amygdala stimulation and Pavlovian conditioned stimuli. Cereb Cortex 18: 1961-1972. doi:10 $.1093 /$ cercor/bhm223

McGinty VB, Lardeux S, Taha SA, Kim JJ, Nicola SM. 2013. Invigoration of reward seeking by cue and proximity encoding in the nucleus accumbens. Neuron 78: 910-922. doi:10.1016/j.neuron.2013.04.010

McHugh SB, Marques-Smith A, Li J, Rawlins JNP, Lowry J, Conway M, Gilmour G, Tricklebank M, Bannerman DM. 2013. Hemodynamic responses in amygdala and hippocampus distinguish between aversive and neutral cues during Pavlovian fear conditioning in behaving rats. Eur J Neurosci 37: 498-507. doi:10.1111/ejn.12057

McLean C, Asnaani A, Litz B, Hofmann S. 2011. Gender differences in anxiety disorders: prevalence, course of illness, comorbidity and burden of illness. J Psychiatr Res 45: 1027-1035. doi:10.1161/ CIRCULATIONAHA.110.956839

Mihindou C, Guillem K, Navailles S, Vouillac C, Ahmed SH. 2013. Discriminative inhibitory control of cocaine seeking. Biol Psychiatry 73: 271-279. doi:10.1016/j.biopsych.2012.08.011

Milad MR, Quirk GJ. 2002. Neurons in medial prefrontal cortex signal memory for fear extinction. Nature 420: 713-717. doi:10.1038/ nature01144.1

Milad MR, Quirk GJ. 2012. Fear extinction as a model for translational neuroscience: ten years of progress. Annu Rev Psychol 63: 129-151. doi:10.1146/annurev.psych.121208.131631

Milad MR, Vidal-Gonzalez I, Quirk GJ. 2004. Electrical stimulation of medial prefrontal cortex reduces conditioned fear in a temporally specific manner. Behav Neurosci 118: 389-394. doi:10.1037/0735-7044 .118 .2 .389

Milad MR, Quirk GJ, Pitman RK, Orr SP, Fischl B, Rauch SL. 2007a. A role for the human dorsal anterior cingulate cortex in fear expression. Biol Psychiatry 62: 1191-1194. doi:10.1016/j.biopsych.2007.04.032

Milad MR, Wright CI, Orr SP, Pitman RK, Quirk GJ, Rauch SL. 2007b. Recall of fear extinction in humans activates the ventromedial prefrontal cortex and hippocampus in concert. Biol Psychiatry 62: 446-454. doi:10 $.1016 /$ j.biopsych.2006.10.011

Millan EZ, Furlong TM, McNally GP. 2010. Accumbens shell-hypothalamus interactions mediate extinction of alcohol seeking. J Neurosci 30: 46264635. doi:10.1523/JNEUROSCI.4933-09.2010

Millan EZ, Reese RM, Grossman CD, Chaudhri N, Janak PH. 2015. Nucleus accumbens and posterior amygdala mediate cue-triggered alcohol seeking and suppress behavior during the omission of alcohol-predictive 
cues. Neuropsychopharmacology 40: 2555-2565. doi:10.1038/ npp. 2015.102

Millan EZ, Kim HA, Janak PH. 2017. Optogenetic activation of amygdala projections to nucleus accumbens can arrest conditioned and unconditioned alcohol consummatory behavior. Neuroscience 360: 106-117. doi:10.1016/j.neuroscience.2017.07.044

Mogenson GJ, Jones DL, Yim CY. 1980. From motivation to action: functional interface between the limbic system and the motor system. Prog Neurobiol 14: 69-97. doi:10.1016/0301-0082(80)90018-0

Nicola SM. 2010. The flexible approach hypothesis: unification of effort and cue-responding hypotheses for the role of nucleus accumbens dopamine in the activation of reward-seeking behavior. J Neurosci 30: 16585-16600. doi:10.1523/JNEUROSCI.3958-10.2010

Parkinson JA, Robbins TW, Everitt BJ. 1999. Selective excitotoxic lesions of the nucleus accumbens core and shell differentially affect aversive Pavlovian conditioning to discrete and contextual cues. Psychobiology 27: 256-266.

Parkinson JA, Willoughby PJ, Robbins TW, Everitt BJ. 2000. Disconnection of the anterior cingulate cortex and nucleus accumbens core impairs Pavlovian approach behavior: further evidence for limbic cortical-ventral striatopallidal systems. Behav Neurosci 114: 42-63. doi:10.1037/0735-7044.114.1.42

Pendyam S, Bravo-Rivera C, Burgos-Robles A, Sotres-Bayon F, Quirk GJ, Nair SS. 2013. Fear signaling in the prelimbic-amygdala circuit: a computational modeling and recording study. J Neurophysiol 110: 844 861. doi:10.1152/jn.00961.2012

Perry JL, Carroll ME. 2008. The role of impulsive behavior in drug abuse. Psychopharmacology (Berl) 200: 1-26. doi:10.1007/s00213-008-1173-0

Peters J, LaLumiere RT, Kalivas PW. 2008. Infralimbic prefrontal cortex is responsible for inhibiting cocaine seeking in extinguished rats. J Neurosci 28: 6046-6053. doi:10.1523/JNEUROSCI.1045-08.2008

Peters J, Kalivas PW, Quirk GJ. 2009. Extinction circuits for fear and addiction overlap in prefrontal cortex. Learn Mem 16: 279-288. doi:10 $.1101 / \operatorname{lm} .1041309$

Phelps EA, Delgado MR, Nearing KI, Ledoux JE. 2004. Extinction learning in humans: role of the amygdala and vmPFC. Neuron 43: 897-905. doi:10 $.1016 /$ j.neuron.2004.08.042

Piantadosi PT, Floresco SB. 2014. Prefrontal cortical GABA transmission modulates discrimination and latent inhibition of conditioned fear: relevance for schizophrenia. Neuropsychopharmacology 39: 2473-2484. doi:10.1038/npp.2014.99

Piantadosi PT, Yeates DCM, Wilkins M, Floresco SB. 2017. Contributions of basolateral amygdala and nucleus accumbens subregions to mediating motivational conflict during punished reward-seeking. Neurobiol Learn Mem 140: 92-105. doi:10.1016/j.nlm.2017.02.017

Piantadosi PT, Yeates DCM, Floresco SB. 2018. Cooperative and dissociable involvement of the nucleus accumbens core and shell in the promotion and inhibition of actions during active and inhibitory avoidance. Neuropharmacology 138: 57-71. doi:10.1016/j.neuropharm.2018.05.028

Pohlack ST, Nees F, Ruttorf M, Schad LR, Flor H. 2012. Activation of the ventral striatum during aversive contextual conditioning in humans. Biol Psychol 91: 74-80. doi:10.1016/j.biopsycho.2012.04.004

Quirk GJ, Russo GK, Barron JL, Lebron K. 2000. The role of ventromedial prefrontal cortex in the recovery of extinguished fear. J Neurosci 20: 6225-6231. doi:10.1523/JNEUROSCI.20-16-06225.2000

Ray MH, Russ AN, Walker RA, McDannald MA. 2020. The nucleus accumbens core is necessary to scale fear to degree of threat. J Neurosci 40: 4750-4760. doi:10.1523/JNEUROSCI.0299-20.2020

Resstel LBM, Souza RF, Guimarães FS. 2008. Anxiolytic-like effects induced by medial prefrontal cortex inhibition in rats submitted to the Vogel conflict test. Physiol Behav 93: 200-205. doi:10.1016/j.physbeh.2007.08.009

Rey CD, Lipps J, Shansky RM. 2014. Dopamine D1 receptor activation rescues extinction impairments in low-estrogen female rats and induces cortical layer-specific activation changes in prefrontal-amygdala circuits. Neuropsychopharmacology 39: 1282-1289. doi:10.1038/npp.2013.338

Riedel G, Harrington NR, Hall G, Macphail EM. 1997. Nucleus accumbens lesions impair context, but not cue, conditioning in rats. Neuroreport 8: 2477-2481. doi:10.1097/00001756-199707280-00013

Rodriguez-Romaguera J, Monte FHMD, Quirk GJ. 2012. Deep brain stimulation of the ventral striatum enhances extinction of conditioned fear. Proc Natl Acad Sci 109: 8764-8769. doi:10.1073/pnas.1200782109

Rozeske RR, Jercog D, Karalis N, Chaudun F, Khoder S, Girard D, Winke N, Herry C. 2018. Prefrontal-periaqueductal gray-projecting neurons mediate context fear discrimination. Neuron 97: 898-910.e6. doi:10 .1016/j.neuron.2017.12.044

Sangha S, Chadick JZ, Janak PH. 2013. Safety encoding in the basal amygdala. J Neurosci 33: 3744-3751. doi:10.1523/JNEUROSCI.3302-12.2013

Sangha S, Robinson PD, Greba Q, Davies DA, Howland JG. 2014. Alterations in reward, fear and safety cue discrimination after inactivation of the rat prelimbic and infralimbic cortices. Neuropsychopharmacology 39: 24052413. doi:10.1038/npp.2014.89
Schiller D, Levy I, Niv Y, LeDoux JE, Phelps EA. 2008. From fear to safety and back: reversal of fear in the human brain. J Neurosci 28: 11517-11525. doi:10.1523/JNEUROSCI.2265-08.2008

Schumacher A, Vlassov E, Ito R. 2016. The ventral hippocampus, but not the dorsal hippocampus is critical for learned approach-avoidance decision making. Hippocampus 26: 530-542. doi:10.1002/hipo.22542

Schumacher A, Villaruel FR, Ussling A, Riaz S, Lee ACH, Ito R. 2018. Ventral hippocampal CA1 and CA3 differentially mediate learned approachavoidance conflict processing. Curr Biol 28: 1318-1324.e4. doi:10.1016/ j.cub.2018.03.012

Schwienbacher I, Fendt M, Richardson R, Schnitzler HU. 2004. Temporary inactivation of the nucleus accumbens disrupts acquisition and expression of fear-potentiated startle in rats. Brain Res 1027: 87-93. doi:10.1016/j.brainres.2004.08.037

Seif T, Chang S-J, Simms JA, Gibb SL, Dadgar J, Chen BT, Harvey BK, Ron D, Messing RO, Bonci A, et al. 2013. Cortical activation of accumbens hyperpolarization-active NMDARs mediates aversion-resistant alcohol intake. Nat Neurosci 16: 1094-1100. doi:10.1038/nn.3445

Sesack SR, Deutch AY, Roth RH, Bunney BS. 1989. Topographical organization of the efferent projections of the medial prefrontal cortex in the rat: an anterograde tract-tracing study with Phaseolus vulgaris leucoagglutinin. J Comp Neurol 290: 213-242. doi:10.1002/cne .902900205

Sierra-Mercado D, Padilla-Coreano N, Quirk GJ. 2011. Dissociable roles of prelimbic and infralimbic cortices, ventral hippocampus, and basolateral amygdala in the expression and extinction of conditioned fear. Neuropsychopharmacology 36: 529-538. doi:10.1038/npp.2010.184

Sotres-Bayon F, Quirk GJ. 2010. Prefrontal control of fear: more than just extinction. Curr Opin Neurobiol 20: 231-235. doi:10.1016/j.conb.2010 .02 .005

St Onge JR, Stopper CM, Zahm DS, Floresco SB. 2012. Separate prefrontal-subcortical circuits mediate different components of risk-based decision making. J Neurosci 32: 2886-2899. doi:10.1523/ JNEUROSCI.5625-11.2012

Stopper CM, Floresco SB. 2011. Contributions of the nucleus accumbens and its subregions to different aspects of risk-based decision making. Cogn Affect Behav Neurosci 11: 97-112. doi:10.3758/s13415-010-0015-9

van Holstein M, Floresco SB. 2020. Dissociable roles for the ventral and dorsal medial prefrontal cortex in cue-guided risk/reward decision making. Neuropsychopharmacology 45: 683-693. doi:10.1038/ s41386-019-0557-7

van Holstein M, MacLeod PE, Floresco SB. 2020. Basolateral amygdala nucleus accumbens circuitry regulates optimal cue-guided risk/reward decision making. Prog Neuropsychopharmacol Biol Psychiatry 98: 109830 doi:10.1016/j.pnpbp.2019.109830

Vertes RP. 2004. Differential projections of the infralimbic and prelimbic cortex in the rat. Neurobiol Learn Mem 51: 32-58. doi:10.1002/syn.10279

Vidal-Gonzalez I, Vidal-Gonzalez B, Rauch SL, Quirk GJ. 2006. Microstimulation reveals opposing influences of prelimbic and infralimbic cortex on the expression of conditioned fear. Learn Mem 13: 728-733. doi:10.1101/lm.306106

Wendler E, Gaspar JCC, Ferreira TL, Barbiero JK, Andreatini R, Vital MABF, Blaha CD, Winn P, Da Cunha C. 2013. The roles of the nucleus accumbens core, dorsomedial striatum, and dorsolateral striatum in learning:performance and extinction of Pavlovian fear-conditioned responses and instrumental avoidance responses. Neurobiol Learn Mem 109: 27-36. doi:10.1016/j.nlm.2013.11.009

Whishaw IQ, Dringenberg HC. 1991. How does the rat (Rattus norvegicus) adjust food-carrying responses to the influences of distance, effort, predatory odor, food size, and food availability? Psychobiology 19: 251-261. doi:10.3758/BF03332076

Wright CI, Beijer AV, Groenewegen HJ. 1996. Basal amygdaloid complex afferents to the rat nucleus accumbens are compartmentally organized. $J$ Neurosci 16: 1877-1893. doi:10.1523/JNEUROSCI.16-05-01877.1996

Yang H, de Jong JW, Tak YE, Peck J, Bateup HS, Lammel S. 2018. Nucleus accumbens subnuclei regulate motivated behavior via direct inhibition and disinhibition of VTA dopamine subpopulations. Neuron 97: 434449.e4. doi:10.1016/j.neuron.2017.12.022

Yeates DCM, Ussling A, Lee ACH, Ito R. 2019. Double dissociation of learned approach-avoidance conflict processing and spatial pattern separation along the dorsoventral axis of the dentate gyrus. Hippocampus 30: 596609. doi:10.1002/hipo.23182

Yun IA, Wakabayashi KT, Fields HL, Nicola SM. 2004. The ventral tegmental area is required for the behavioral and nucleus accumbens neuronal firing responses to incentive cues. J Neurosci 24: 2923-2933. doi:10 $.1523 /$ JNEUROSCI.5282-03.2004

Zahm DS, Brog JS. 1992. On the significance of subterritories in the "accumbens" part of the rat ventral striatum. Neuroscience 50: 751-767. doi:10.1016/0306-4522(92)90202-D

Received May 4, 2020; accepted in revised form July 2, 2020. 


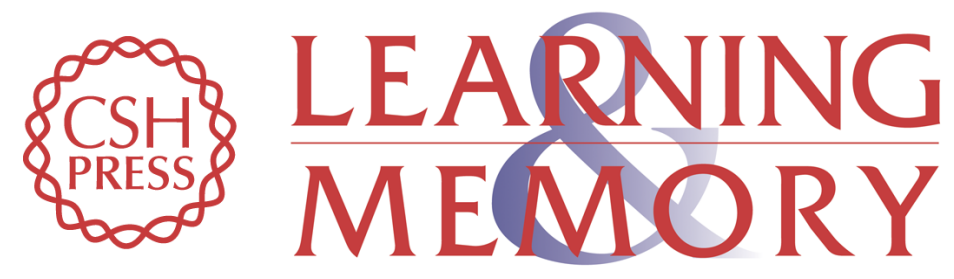

\section{Prefrontal cortical and nucleus accumbens contributions to discriminative conditioned suppression of reward-seeking}

Patrick T. Piantadosi, Dylan C.M. Yeates and Stan B. Floresco

Learn. Mem. 2020, 27:

Access the most recent version at doi:10.1101/Im.051912.120

\begin{tabular}{|c|c|}
\hline References & $\begin{array}{l}\text { This article cites } 134 \text { articles, } 33 \text { of which can be accessed free at: } \\
\text { http://learnmem.cshlp.org/content/27/10/429.full.html\#ref-list-1 }\end{array}$ \\
\hline $\begin{array}{r}\text { Creative } \\
\text { Commons } \\
\text { License }\end{array}$ & $\begin{array}{l}\text { This article is distributed exclusively by Cold Spring Harbor Laboratory Press for the } \\
\text { first } 12 \text { months after the full-issue publication date (see } \\
\text { http://learnmem.cshlp.org/site/misc/terms.xhtml). After } 12 \text { months, it is available under } \\
\text { a Creative Commons License (Attribution-NonCommercial } 4.0 \text { International), as } \\
\text { described at http://creativecommons.org/licenses/by-nc/4.0/. }\end{array}$ \\
\hline $\begin{array}{l}\text { Email Alerting } \\
\text { Service }\end{array}$ & $\begin{array}{l}\text { Receive free email alerts when new articles cite this article - sign up in the box at the } \\
\text { top right corner of the article or click here. }\end{array}$ \\
\hline
\end{tabular}

